\title{
Use of Cellular Automata-Based Artificial Neural Networks For Detection and Prediction of Land Use Changes in North Eastern Dhaka City
}

\section{Foyezur Rahman}

Military Institute of Science and Technology

Md. Tauhid Ur Rahman ( $\sim$ tauhid_cee@yahoo.com)

Military Institute of Science and Technology

\section{Research Article}

Keywords: Urbanization, LST, UHI, NDVI, NDBI, CA-ANN

Posted Date: November 15th, 2021

DOI: https://doi.org/10.21203/rs.3.rs-993126/v1

License: (c) (i) This work is licensed under a Creative Commons Attribution 4.0 International License.

Read Full License 
1 Use of Cellular Automata-based Artificial Neural Networks for Detection and Prediction of Land Use Changes in North Eastern Dhaka City

3

4 Foyezur Rahman

5 Professor, Department of Civil Engineering, Military Institute of Science and Technology

6 (MIST), Dhaka-1216, Bangladesh

7 Md. Tauhid Ur Rahman*

8 Professor, Department of Civil Engineering, Military Institute of Science and Technology

9 (MIST), Dhaka-1216, Bangladesh

10

$11{ }^{*}$ Corresponding Author:

12 tauhid_ce@@yahoo.com

13 Department of Civil Engineering, Military Institute of Science and Technology

14 Phone: +880 1965-965956 


\section{Abstract}

16 The purpose of this study was to examine the pattern of change in Land Use Land Cover 17 (LULC) and Land Surface Temperature (LST) in Mirpur and its surrounding area (north18 eastern part of Dhaka) over the last 30 years using Landsat Satellite images and remote 19 sensing indices, and to develop relationships between LULC types and LST, as well as to 20 analyze their impact on local warming. Using this analyzed data, a further projection of 21 LULC and LST change over the next two decades was made. From 1989 to 2019, five-year 22 intervals of Landsat 4-5 TM and Landsat 8 OLI pictures were utilized to track the 23 relationship between LULC changes and LST. Cellular Automata-based Artificial Neural 24 Network (CA-ANN) algorithm was used to model the LULC and LST maps for the year 25 2039. Two environmental indices were analyzed to determine their link with LST: the 26 Normalized Difference Vegetation Index (NDVI) and the Normalized Difference Built-up 27 Index (NDBI). The link between LST and LULC types indicates that built-up area raises 28 LST by substituting non-evaporating surfaces for natural vegetation. The average surface 29 temperature has been increasing steadily for the previous 30 years. For the year 2019, it was 30 determined that roughly 86 percent of total land area has been converted to built-up area and 31 that 89 percent of land area has an LST greater than $28^{\circ} \mathrm{C}$. According to the study, if the 32 current trend continues, 72 percent of the Mirpur area is predicted to see temperatures near $3332^{\circ} \mathrm{C}$ in 2039 . Additionally, LST had a significant positive association with NDBI and a 34 negative correlation with NDVI. The overall accuracy of LULC was greater than 90\%, with 35 a Kappa coefficient of 0.83 . The study may assist urban planners and environmental 36 engineers in comprehending and recommending effective policy measures and plans to 37 mitigate the consequences of LULC.

38 Keywords: Urbanization, LST, UHI, NDVI, NDBI, CA-ANN 


\section{Introduction}

40 Bangladesh is one of the heavily populated countries in South Asia, and over the past century, it

41 has also experienced rapid population growth. The explosion of population growth mainly took

42 place in the City areas. It is estimated that almost all other men, women, and children will be living

43 in urban areas in the future (M. Rahman, A. S. Aldosary, \& M. Mortoja, 2017). Dhaka, the capital

44 of Bangladesh, is one of the world's fastest expanding megacities (M. Rahman, A. S. Aldosary, \&

45 M. Mortoja, 2017; Dewan \& Yamaguchi, 2009; Meyer \& Turner, 1992). Thus, while rising

46 urbanization in Dhaka is likely to have a significant impact on land cover changes and,

47 subsequently, on the urban microclimate, little is known about these developments. Additionally,

48 it is home to almost 16 million people and covers an area of around 304.16 square kilometers. This

49 city's population has expanded by nearly 11 million people during the last two decades (Dewan \&

50 Yamaguchi, 2009). Dhaka is spreading vertically and horizontally as a result of this population

51 explosion driven primarily by rural-urban migration and partially by natural growth, and these

52 expansions have been highlighted as a major contributor to the increase in Land Surface

53 Temperature (LST) (Al-sharif \& Pradhan, 2014).

54 Urbanization refers to the process of the change of country area to a City area, which is the result

55 of population immigration, administrative services, construction of new infrastructure, and

56 development of industry and service sector. Over the past few years, the Land Use Land Cover

57 (LULC) change mechanism at the national and local level has also drawn the attention of

58 researchers. It is reported that LULC's global spatial dynamics also reveal the connection between

59 land-use change and human activity (Corner, Dewan, \& Chakma, 2014; Dewan \& Yamaguchi,

60 2009; Meyer \& Turner, 1992; M. S. Rahman, Mohiuddin, Kafy, Sheel, \& Di, 2018). Some scholars

61 emphasized the effects on LULC changes by urbanization, believing that population growth and

62 economic development contributed to urban expansion and a large number of water and

63 agricultural land transformations into built-up areas. This transition also affects the local, regional

64 and global ecosystems, including habitat quality, green areas, and destruction of the environment

65 (Dewan, Kabir, Nahar, \& Rahman, 2012; Dewan \& Yamaguchi, 2009; IPCC, 2014; Lilly Rose,

66 2009). The mechanism of LULC transition is complex as the relationship depends on different

67 scales of natural and socio-economic factors (Chen, Zhao, Li, \& Yin, 2006; McKinney, 2002; Tran

68 et al., 2017). The associated factors have an impact on the change in LULC due to the scale effect 
and vulnerability of the land system dynamics and it is, therefore, vital to understand its relation.

70 Meanwhile, accurate prediction for future land use is essentially required to avoid unexpected

71 urbanization, which is necessary to plan and manage land use (Ahmed, 2011a; Balogun \& Ishola,

72 2017; M. Rahman et al., 2017; M. S. Rahman et al., 2018).

73 Human migration to Cities causes urban areas to grow every year and creates rapid changes to 74 their ecosystems, biodiversity, natural landscapes, and the environment (McKinney, 2002). More 75 than $70 \%$ of the world's population is anticipated to live in urban areas in the next 30 years (Celik, 76 Kaya, Alganci, \& Seker, 2019; Grimmond, 2007; Handayanto, Kim, \& Tripathi, 2017; Kafy, 77 Islam, Ferdous, Khan, \& Hossain, 2019; M. Rahman et al., 2017; Ullah et al., 2019). While this 78 development is a sign of economic growth and economic stability in the region, it has several short 79 and long-term consequences. Over the last decade, geographers, urban planners, and climate 80 scientists have been paying considerable attention to elevated LST over urban areas (Al-sharif \& 81 Pradhan, 2014; Kafy et al., 2019; Maduako, Yun, \& Patrick, 2016; M. Rahman, 2016; Zheng, 82 Shen, Wang, \& Hong, 2015; Zine El Abidine, Mohieldeen, Mohamed, Modawi, \& Al-Sulaiti, 83 2014). Several studies suggest that population expansion appears to increase the average LST in 84 urban environments by $2-4^{\circ} \mathrm{C}$ in contrast with rural areas (Maimaitiyiming et al., 2014; Mozumder 85 \& Tripathi, 2014; Thapa \& Murayama, 2009; Yu, Guo, \& Wu, 2014). Increased LSTs and Urban 86 Heat Island (UHI) impact have been associated with high energy consumption, air pollution, and 87 health issues, including the deaths of children and elders from asthma and heat stroke (Ahmed, 88 Kamruzzaman, Zhu, Rahman, \& Choi, 2013; Maduako et al., 2016; M. T. Rahman, A. S. Aldosary, 89 \& M. Mortoja, 2017; M. T. Rahman \& Rashed, 2015; Scarano \& Sobrino, 2015; Zhi-hao, Wenjuan, Ming-hua, Karnieli, \& Berliner, 2011; Zhou, Huang, \& Cadenasso, 2011).

91 Bangladesh is one among the world's most populous countries, according to the "Bangladesh Delta 92 Plan 2100." The overall population density, according to 2011 census statistics, is around 1,015 93 persons per square kilometer. Recent UN figures indicate that roughly $25 \%$ of Bangladesh's current 94 population resides in urban areas. More than half of this urban population resides in four major 95 cities: Dhaka, Chittagong, Khulna, and Rajshahi. The population density is currently estimated to 96 be over 34,000 people per square kilometer, placing Dhaka among the world's most densely 97 inhabited cities. In 1976, the rural settlement area was projected to be 885,637 hectares, accounting 98 for 6.1 percent of the total land area of the nation. Rural settlement area rose at a quicker pace over 
time, reaching $10 \%(1,458,031 \mathrm{ha})$ in 2000 and 12.1 percent $(1,766,123 \mathrm{ha})$ in 2010 . (van

100 Scheltinga, Quadir, \& Ludwig, 2015).

101 Examining LULC change in the last few decades has become an increasing concern because of 102 biodiversity decreasing, habitat changing, and altering the regional and global climate patterns and 103 composition (J. Li \& Zhao, 2003; Lilly Rose, 2009; Mishra \& Rai, 2016). It can be challenging, 104 complicated, and likely to yield contradictory results to detect and tests changes in LULC through 105 direct field visits (Meyer \& Turner, 1992; M. Rahman, 2016; Zheng et al., 2015). Over the past 106 few decades, developments and integration of Remote Sensing and Geographic Information 107 System (GIS) technologies have overcome most of the constraints and are now powerful methods 108 for assessing, monitoring changes in LST and LULCs (Corner et al., 2014; Fu \& Weng, 2018; Hart $109 \&$ Sailor, 2009; Islam \& Ahmed, 2011). Even since the early 1970s, the use of remote sensing 110 techniques to measure LSTs and investigate the development and spatial distribution of UHIs has 111 been quite successful. Research has identified that massive changes of various LULC components 112 (water bodies, vegetation, and agricultural lands) contribute to the increase in LST which 113 significantly stimulus the generation of UHI effect (Bahi, Rhinane, Bensalmia, Fehrenbach, \& 114 Scherer, 2016; Lambin, 1999; Maduako et al., 2016). LST is recognized as one of the main factors 115 for urban microclimate warming. Several local issues are closely linked to the LST, such as 116 biophysical hazards (e.g. heat stress), air pollution, and public health concerns (Amiri, Weng, 117 Alimohammadi, \& Alavipanah, 2009; Chander, Markham, \& Helder, 2009; Gutman, Huang, 118 Chander, Noojipady, \& Masek, 2013; Streutker, 2003). As the rise in surface temperature 119 contributes significantly to the deterioration of the ecological balance, it is, therefore, important to 120 obtain LST as a first and primary step and then to model possible LST so that policies can be 121 implemented to mitigate the negative environmental impacts (Celik et al., 2019; M. Rahman et al., 122 2017; M. T. Rahman et al., 2017; M. T. Rahman \& Rashed, 2015; Shatnawi \& Abu Qdais, 2019; 123 Weng, Lu, \& Schubring, 2004).

124 As LST is largely dependent on LULC therefore, prediction of LULC for evaluating future change 125 in LST is needed. Cellular Automata-Artificial Neural Network (CA-ANN) model provides a solid 126 understanding of the complexities of the spatial system to evaluate and predict LULC changing 127 patterns. To monitor previous and existing LULC and determine the potential impacts of LULC 128 on the city area, this study mainly focuses on predicting future changes of LULC and identifies its 
129 impacts on future LST. Using a CA-ANN model, the simulation of future land cover can be 130 analysed. The CA-ANN model, together with the geographical information system, is widely 131 regarded as the most powerful tool for modelling the probabilities of the spatiotemporal shift in 132 LULC (Arsanjani, Helbich, Kainz, \& Boloorani, 2013; Santé, García, Miranda, \& Crecente, 2010).

133 Under these circumstances stated above, the research is primarily planned to investigate LULC 134 and LST shifts in the past two decades (1989-2019) through the use of recent and historically 135 archived Landsat satellite images in Mirpur and its surrounding area. Also, a simulation will be 136 done by using ANN-based CA algorithm to predict the future growth and surface temperature of 137 the Mirpur and its surrounding area for the year 2039. 


\section{Materials and Methods}

140

2.1 Study Area

141 "Dhaka City," is known as "Dhaka Metropolitan Area (DMP)" situated on the eastern bank of the 142 river Buriganga, near Bangladesh's geographical center at a latitude of $23^{\circ} 43^{\prime}$ North and $90^{\circ} 24^{\prime}$ 143 East longitude (Fig. 1). DMP covers a total area of 306.04 sq. km (Ahmed, 2011b).

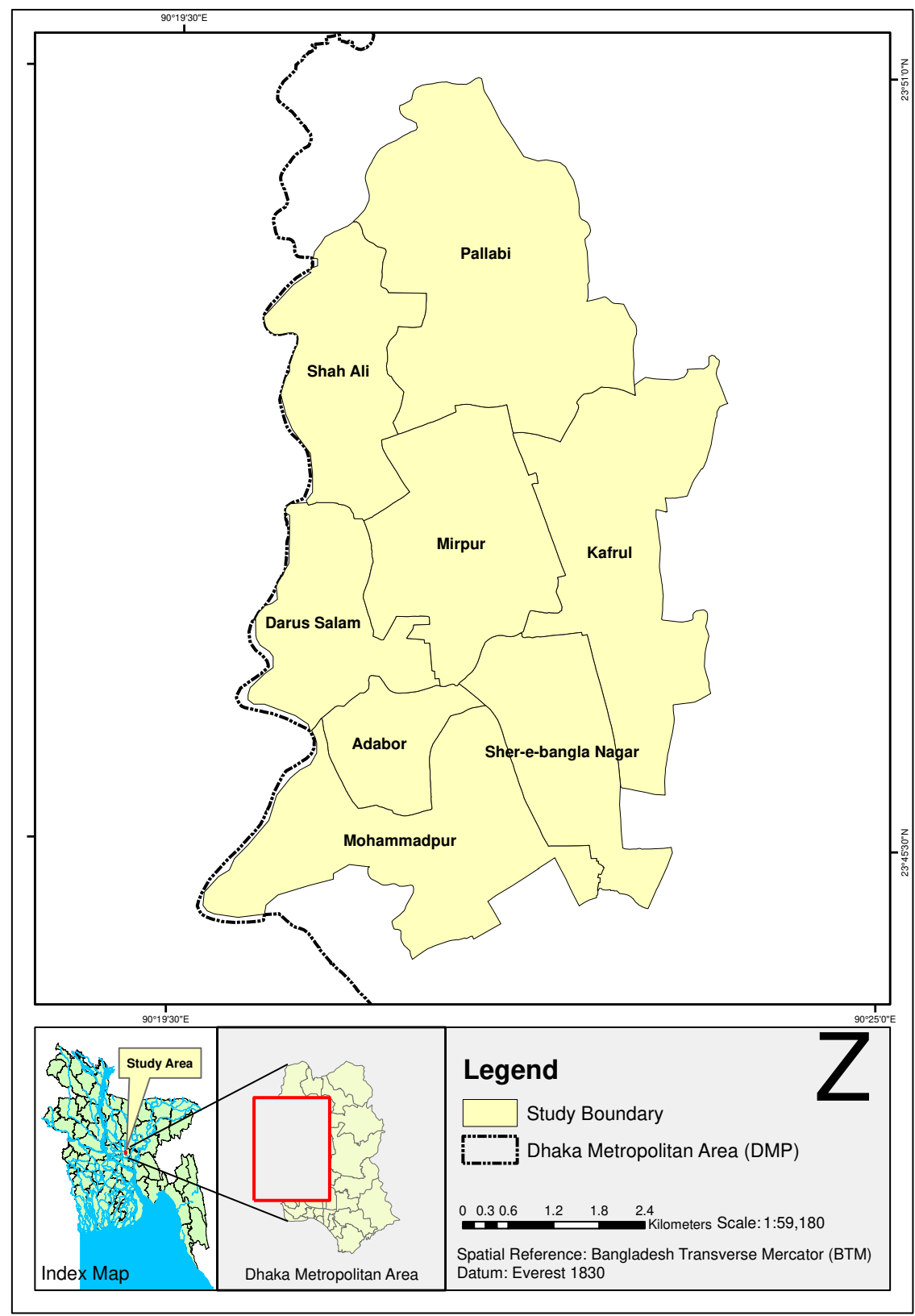

Fig. 1: Location of the study area 
145 Historical data indicates that, Mirpur and its surrounding area faces tremendous LULC change and 146 so LST from last 30 years. Therefore, to scrutinize the analysis, Mirpur and its surrounding area 147 (north-eastern part of Dhaka) has been selected for the main study area of this analysis. Geographic 148 location of the study area is located between 90²1'42.195"E to 90²1'27.465"E and $14923^{\circ} 50^{\prime} 55.249^{\prime \prime} \mathrm{N}$ to $23^{\circ} 44^{\prime} 46.334^{\prime \prime} \mathrm{N}$. The study area is total $48.834 \mathrm{sq}$. $\mathrm{km}$. The area of interest is 150 situated in DMP area. Eight (8) Thana boundaries such as Mirpur, Adabor, Mohammadpur, 151 Pallabi, Darus Salam, Shah Ali, Kafrul and Sher-e-Bangla Nagar cover the study region.

\section{$152 \quad 2.2$ Methodology}

153 The main research methodology is focused primarily on satellite images. Satellite image covers 154 larger area with significant spectral bands which can be used for several environmental analysis. 155 On the other hand, satellite image can provide past data which can be significant for past to present 156 trend analysis. Using this trend analysis, and building up an equation, future can also be predicted.

157 Landsat images can be collected from the United States Geological Survey (USGS) website. 158 Before 2013, Landsat TM 4-5 data and after then Landsat OLI 8 data have been used for the study. 159 All the Landsat images are taken for the month of November to get cloud free images. Table 1 160 displays information regarding satellite images.

161 Table 1: Information of used satellite images

\begin{tabular}{|c|c|c|c|c|c|}
\hline $\begin{array}{c}\text { Satellite } \\
\text { data }\end{array}$ & $\begin{array}{c}\text { Date of } \\
\text { acquisition }\end{array}$ & Sensor & $\begin{array}{l}\text { Band } \\
\text { No. }\end{array}$ & $\begin{array}{c}\text { Spectral range } \\
\text { (Wavelength } \\
\mu \mathrm{m})\end{array}$ & $\begin{array}{c}\text { Spatial } \\
\text { resolution, m }\end{array}$ \\
\hline \multirow{6}{*}{$\begin{array}{l}\text { Landsat 4- } \\
\qquad 5\end{array}$} & November 04, & \multirow{6}{*}{$\mathrm{TM}$} & 1 & $0.45-0.52$ & 30 \\
\hline & 1989 & & 2 & $0.52-0.60$ & 30 \\
\hline & November 18 , & & 3 & $0.63-0.69$ & 30 \\
\hline & 1994; & & 4 & $0.76-0.90$ & 30 \\
\hline & November 16, & & 5 & 1.551 .75 & 30 \\
\hline & $\begin{array}{c}1999 ; \\
\text { November } 13,\end{array}$ & & 6 & 10.4012 .50 & $\begin{array}{c}120 \text { resampled } \\
\text { to } 30\end{array}$ \\
\hline
\end{tabular}




\begin{tabular}{|c|c|c|c|c|c|}
\hline $\begin{array}{c}\text { Satellite } \\
\text { data }\end{array}$ & $\begin{array}{c}\text { Date of } \\
\text { acquisition }\end{array}$ & Sensor & $\begin{array}{l}\text { Band } \\
\text { No. }\end{array}$ & $\begin{array}{c}\text { Spectral range } \\
\text { (Wavelength } \\
\mu \mathrm{m})\end{array}$ & $\begin{array}{l}\text { Spatial } \\
\text { resolution, m }\end{array}$ \\
\hline & $\begin{array}{c}2004 ; \\
\text { November } 11, \\
2009\end{array}$ & & 7 & 2.082 .35 & 30 \\
\hline \multirow{11}{*}{ Landsat 8} & \multirow{11}{*}{$\begin{array}{l}\text { November } 25 \text {, } \\
2014 ; \\
\text { November } 23 \text {, } \\
2019\end{array}$} & \multirow{9}{*}{ OLI } & 1 & $0.43-0.45$ & 30 \\
\hline & & & 2 & $0.45-0.51$ & 30 \\
\hline & & & 3 & $0.64-0.67$ & 30 \\
\hline & & & 4 & $0.53-0.59$ & 30 \\
\hline & & & 5 & $0.85-0.88$ & 30 \\
\hline & & & 6 & $1.57-1.65$ & 30 \\
\hline & & & 7 & $2.11-2.29$ & 30 \\
\hline & & & 8 & $1.36-1.38$ & 15 \\
\hline & & & 9 & $0.50-0.68$ & 30 \\
\hline & & TRIS 1 & 10 & $10.60-11.19$ & $\begin{array}{c}100 \text { resampled } \\
\text { to } 30\end{array}$ \\
\hline & & TRIS 2 & 11 & $11.50-12.51$ & $\begin{array}{c}100 \text { resampled } \\
\text { to } 30\end{array}$ \\
\hline
\end{tabular}

162 After downloading the data, sequentially landcover, LST, NDVI and NDBI were calculated. Using 163 the data, LST and land cover were predicted for future 30 years. Meanwhile, the calculated data 164 were validated using temperature data collected from Bangladesh Metrological Department 165 (BMD). In addition, frequent field visits were taken place to validate the measured data by 166 interviewing local respondents. Afterwards, a correlation analysis was carried out among LST, 167 NDVI, and NDBI. The whole methodological steps are given by flow diagram (Fig. 2). 


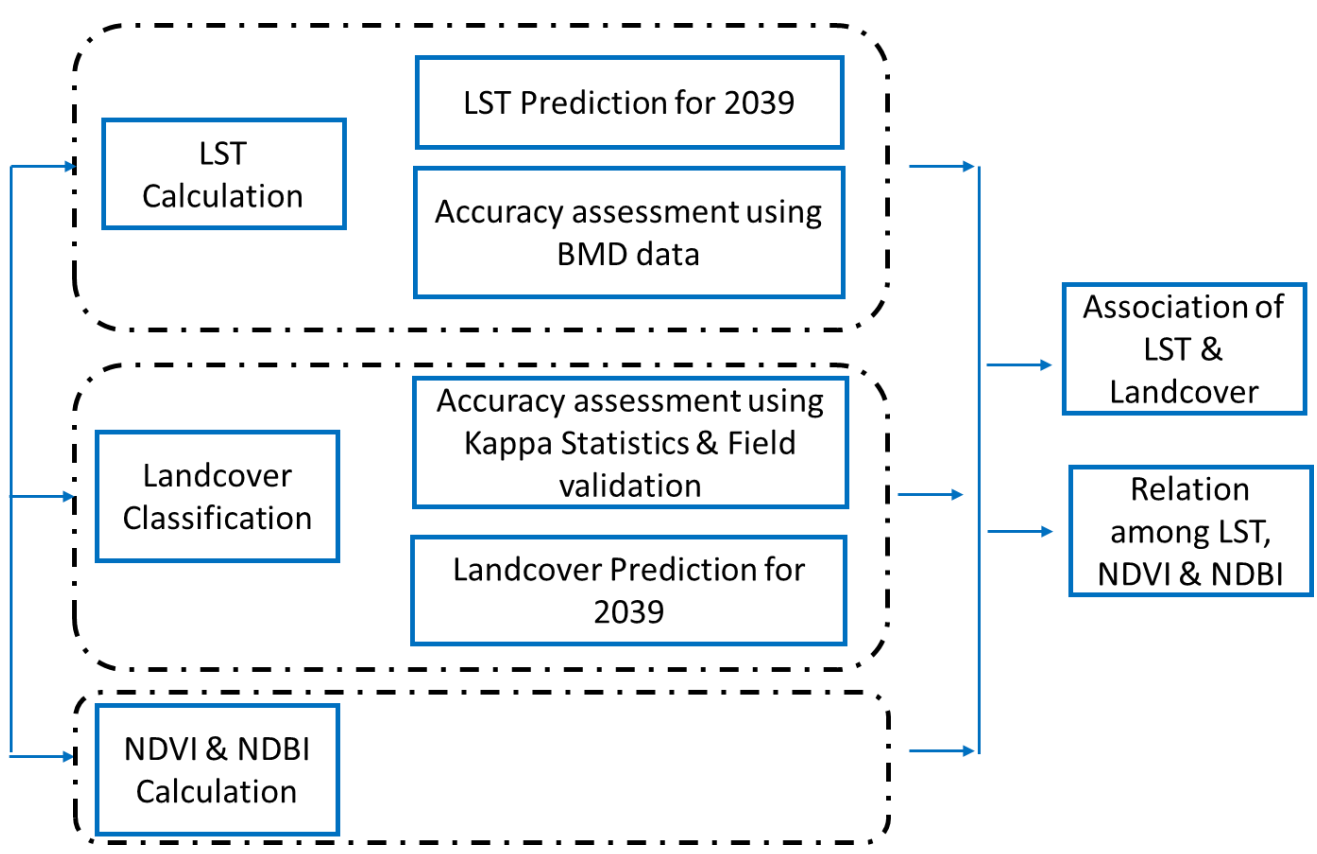

Fig. 2: Methodological flow diagram of the study

\subsubsection{Land Use Land Cover Classification}

171 ArcGIS 10.6.1 software was used to combine the satellite images obtained. To choose training

172 samples and identify the various LULC classes, a True Color Composite (TCC) was created using

173 appropriate band combinations for all images (d'Entremont \& Thomason, 1987; Good \& Giordano,

174 2019). Landsat images were categorized using the Maximum Likelihood Supervised Classification

175 (MLSC) approach into four major LULC classes (water body, built-up area, vegetation, and barren

176 terrain) for the years 1989, 1994, 1999, 2004, 2014, and 2019. A total of around 25 samples were

177 gathered to generate LULC maps for each LULC class. Each categorized map has been assessed

178 for accuracy using the kappa index (Foody, 2002; Pontius Jr \& Millones, 2011; Story \& Congalton, 179 1986).

\subsubsection{Estimation of Land Surface Temperature (LST)}

181 a. Top of Atmospheric Spectral Radiance: Top of Atmospheric Spectral Radiance (TOA) was 182 retrieved by using following equation 1 (Liu \& Zhang, 2011).

$$
L_{\lambda}=M_{L} \times Q_{c a l}+A_{L}
$$


184 Where $M_{L}$ was represented as the band-specific multiplicative rescaling factor, $Q_{c a l}$ was the Band $18510, A_{L}$ is the band-specific additive rescaling factor.

b. Sensor Brightness Temperature Estimation $\left(\boldsymbol{T}_{\boldsymbol{i}}\right)$ : First and foremost, conversion from the

187 spectral radiance of thermal infrared band to active radiance sensor brightness temperature was 188 calculated by equation 2 (Liu \& Zhang, 2011; Maduako et al., 2016; M. Rahman et al., 2017; 189 Sholihah \& Shibata, 2019).

190

$$
T_{i}=\frac{K_{2}}{\ln \left(\frac{k_{1}}{L_{\lambda}}+1\right)}
$$

191 Here, $K_{1}$ and $K_{2}$ are the calibration constant; $K_{1}$ in $\mathrm{W} /\left(\mathrm{m}^{2}\right.$.sr. $\left.\mu \mathrm{m}\right)$ and $\mathrm{K}_{2}$ in kelvin respectively. 192 The value of $\mathrm{K}_{1}$ and $\mathrm{K}_{2}$ for Landsat 4-5 and Landsat 8 are given as following Table 2 (Liu \& 193 Zhang, 2011).

194 Table 2: Landsat Thermal Bands Calibration Constants

\begin{tabular}{ccc}
\hline Constant & Unit $_{1}: \mathrm{W} /\left(\mathrm{m}^{2} \cdot \mathrm{sr} . \mu \mathrm{m}\right)$ & Unit $\mathrm{K}_{2}:$ Kelvin \\
\hline Landsat 4-5 TM & 607.76 & 1260.56 \\
Landsat8 TIRS (band 10) & 774.8853 & 1321.0789 \\
Landsat8 TIRS (band 11) & 480.8883 & 1201.1442 \\
\hline
\end{tabular}

195 c. Retrieving LST: Thermal infrared wavelengths are used to determine Top of Atmosphere 196 (TOA) brightness. Meanwhile, to get an accurate land surface brightness temperature, atmospheric 197 influences such as upward emission and downward irradiance reflected from the surface should be 198 adjusted. Calculating the land surface spectral emissivity $(\mathcal{E})$ enables the aforementioned 199 adjustment to be made. Meanwhile, some elements such as water content, chemical composition, 200 structure, and roughness all affect the emissivity of the surface (Zine El Abidine et al., 2014). 201 Numerous scholars have demonstrated that the surface emissivity is highly correlated with the 202 NDVI, and so the emissivity can be calculated using the NDVI (Ahmed et al., 2013).

203 NDVI can be calculated using the following equation 3 using the reflectance values of the Visible 204 and Near Infrared bands (Ahmed et al., 2013). 
206 Where, $B_{N I R}, B_{R E D}$ were the pixel values of near-infrared and red bands. Using the NDVI value 207 the Proportion of Vegetation $(\mathrm{Pv})$ can be calculated to measure land surface emissivity $(\mathcal{E})$ by using 208 equation 4 (Liu \& Zhang, 2011).

$$
P_{v}=\left(\frac{N D V I-N D V I_{\min }}{N D V I-N D V I_{\max }}\right)^{2}
$$

210 Using Pv, land surface emissivity $(\mathcal{E})$ can be measured by following equation 5 (d'Entremont \& 211 Thomason, 1987; Good \& Giordano, 2019).

$$
\varepsilon=0.004 \times P_{v}+0.986
$$

213 The land surface temperatures corrected for spectral emissivity $(\varepsilon)$ was computed by the following 214 equation 6 (Avdan \& Jovanovska, 2016; Chaudhuri \& Mishra, 2016; Ullah et al., 2019; Xiong et 215 al., 2012).

$$
L S T=\frac{T_{i}}{1+\left(\lambda \times \frac{T_{i}}{\rho}\right) \times \ln (\varepsilon)}
$$

217 Here, LST represents land surface temperature; $T_{i}$ was the sensors brightness temperature. The 218 emitted radiance's wavelength was indicated as $\lambda$ and $\varepsilon$ indicates the land surface spectral 219 emissivity.

220 In addition,

$$
\rho=h \frac{c}{\sigma}
$$

222 Here, the value of $\rho$ is $1.438 \times 10^{-2} \mathrm{mk}$ (equation 7). Where $\mathrm{h}$ indicates Plank's constant which is 223 equal to $6.626 \times 10^{-34} \mathrm{Js}$, c indicates the velocity of light, which is equal to $2.998 \times 10^{8} \mathrm{~ms}^{-2}$ and $\sigma$ is 224 the Boltzmann constant $\left(5.67 \times 10^{-8} \mathrm{Wm}^{2} \mathrm{k}^{-4}=1.38 \times 10^{-23} \mathrm{JK}^{-1}\right)$ (Zine El Abidine et al., 2014).

225 Daily temperature data collected from the Bangladesh Meteorological Department (BMD) located 226 at Agargaon, Dhaka was used for validation of estimated LST. 
228 The CA-ANN model is designed to simulate land-use changes through a multiple output neuron.

229 The network output layer decides the possibilities of multiple land-uses with multiple output 230 neurons. The appropriate parameters for the simulation are calculated automatically by the neural 231 network training process. The CA-ANN model does not include specific transfer rules. The only 232 function is to train the neural network to achieve empirical parameter values. Many factors can be 233 added to the model to improve the precise simulation. A combination of Cellular Automata and 234 ANN Models will produce a better LULC and LST transition spatio-temporal pattern (Mondal, 235 Sharma, Garg, \& Kappas, 2016; Parsa, Yavari, \& Nejadi, 2016).

236 The LST and LULC for the year 2039 with the help of MOLUSCE plug-in in QGIS 2.18 is 237 typically predicted with an ANN. ANN is an effective method that helps to forecast future LST 238 and LULC using data sets from previous years (Civco, 1993; Z.-L. Li et al., 2013; Maduako et al., 239 2016; Shatnawi \& Abu Qdais, 2019). LST simulation was performed in this study using input 240 parameters LULC images, NDVI, NDBI, latitude and longitude and as output parameters for LST 241 (Gopal \& Woodcock, 1996; Maduako et al., 2016). Besides, the CA-ANN model for the future

242 LULC was used in the prediction of input parameters of road layers, NDBI, NDVI, Latitude and 243 Longitude data. The pixel value data of the images were transformed in ArcGIS software 10.6.1 244 for the better performance of the model. The model was developed using past 20 years data (1999245 2019) as the input parameters for predicting the future year 2039 data. The LST prediction model 246 architecture is shown in Fig. 3.

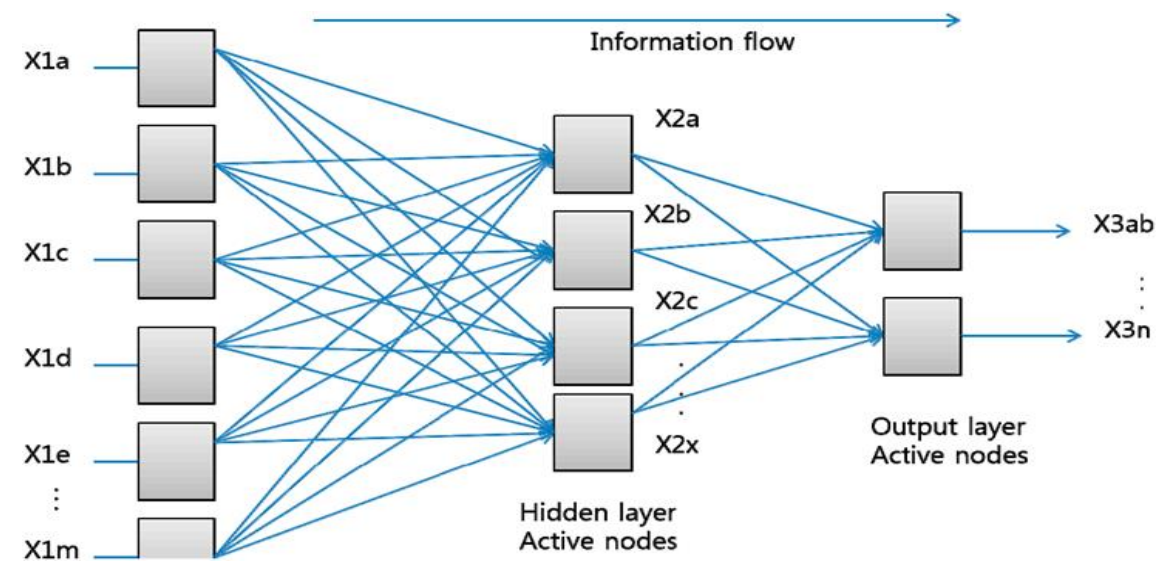


250 The accuracy parameters include the overall accuracy, producer accuracy, user accuracy, and the 251 Kappa coefficients. The overall accuracy is determined by multiplying the error matrix by the total 252 number of corrected samples (equation 8). Historically, the term 'producer accuracy' has been 253 defined as the ratio of the total number of accurate sample units within a category to the total 254 number of sample units within that category (equation 9). This accuracy metric is based on the 255 capability of accurately identifying a reference sample unit and is a real indicator of omission error. 256 When the total number of accurate category sample units is divided by the total number of row 257 sample units on a map (e.g., the total number of row sample units), the result is a commission error 258 measure. This is referred to as "user accuracy" or "reliability," and it reflects the likelihood that a 259 sample unit specified on the map is actually located on the ground (equation 10). Following the 260 calculation of all accuracy parameters, the Kappa coefficient was determined using equation 11. 261 (Congalton \& Green, 2008; Foody, 2002; Pontius Jr \& Millones, 2011; Story \& Congalton, 1986).

$$
\text { Overal Accuracy }=\frac{\text { Total number of corrected classified pixelx (diagonal) }}{\text { toal number of reference pixels }} * 100 \text {--- (8) }
$$

Producer Accuracy $=\frac{\text { number of correctly classified pixelxs in each catagory (diagonal) }}{\text { total number of reference pixels in each catagory }(\text { column total })} * 100$

$$
\text { User Accuracy }=\frac{\text { number of correctly classified pixelxs in each catagory }(\text { diagonal })}{\text { total number of reference pixels in each catagory }(\text { row total })} * 100--(10
$$

\section{Results and Discussions}

271 The LULC map for 1989, 1994, 1999, 2004, 2009, 2014, and 2019 was generated using MLSC 272 (Fig. 4a to 4f). The study's entire area is roughly 48.830 square kilometers. The categorized picture 
273 from 1989 revealed a larger proportion of area for bare terrain, aquatic bodies, and vegetation, 274 respectively, at 35.04 percent, 27.34 percent, and 24.9 percent. For 1989, the built-up area was just 27512.56 percent (Fig. 4a). In 1994, bare ground had the most area (39.20 percent), followed by water 276 bodies (24.63 percent) and vegetation (17.04 percent) (Fig. 4b). In 1994, built-up area increased 277 by $7 \%$ over 1989 levels. The continuing upward trend in bare land (40.45 percent) and built-up 278 area (31.85 percent) was accelerated in 1999, mostly due to growing urbanization. Water bodies $279(8.19 \%)$ and vegetative land $(19.11 \%)$ have saw a decline in recent years due to the transfer of 280 natural surfaces to bare ground and later to built-up land (Fig. 4c). In 2004, bare land (33.15 281 percent) continued to decline due to the conversion of bare land to urban built-up areas (43.76 282 percent ). Filling up water bodies (4.77 percent) and vegetative land (18.32 percent) that were 283 initially bare land and were eventually moved to built-up areas began to speed in 2004. (Fig. 4d).

284 The categorized LULC findings for 2009, 2014, and 2019 were compared (Fig. 4e to 4f) by 285 calculating the percentage change in each LULC class over time. Between 2009 and 2019, the 286 quantity of bare and vegetated land decreased considerably (by roughly 10\%). During the same 287 time span, the built-up area expanded by a factor of two (21 percent of the study area). Finally, the 288 water body declined by $1 \%$ of the studied area between 2009 and 2019.

(a)

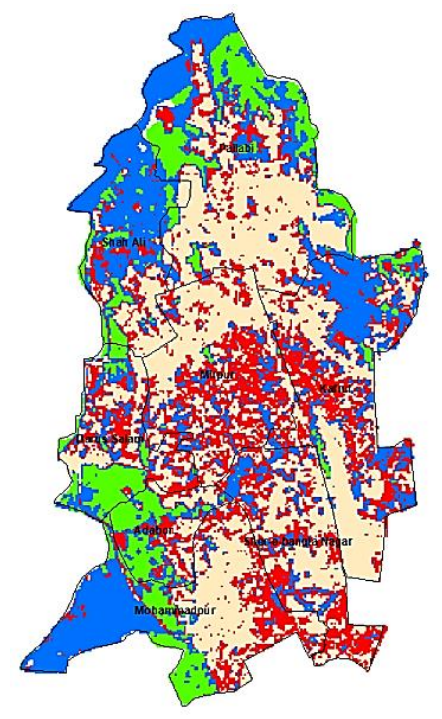

(b)

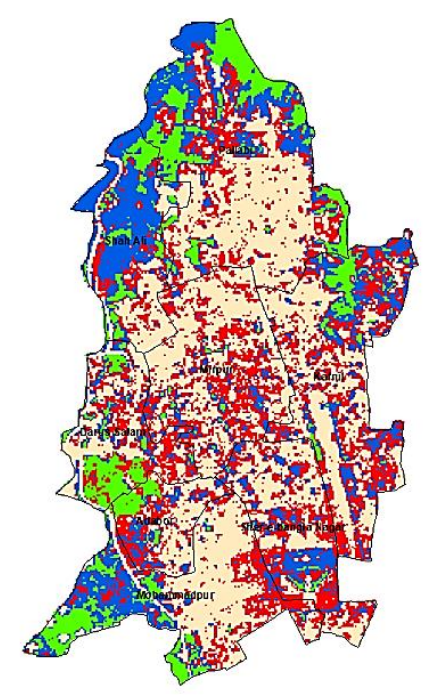

(c)

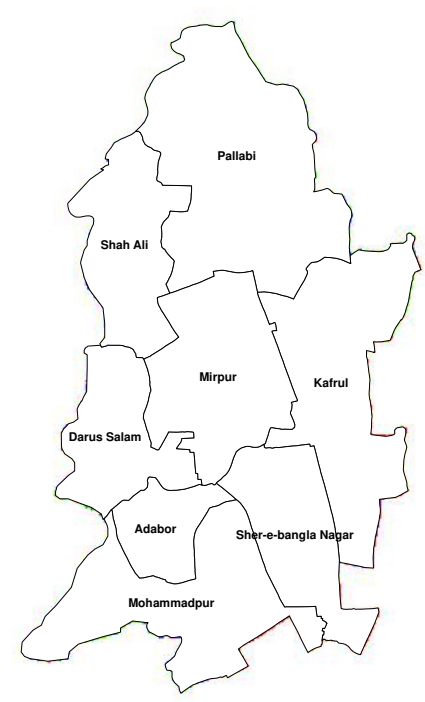

(d)

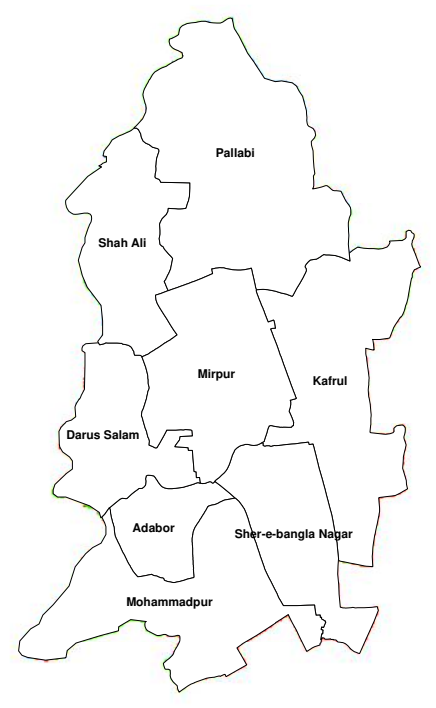


(e)

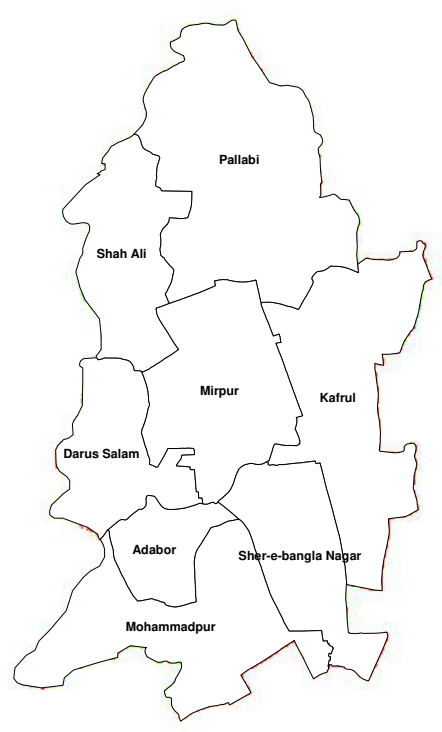

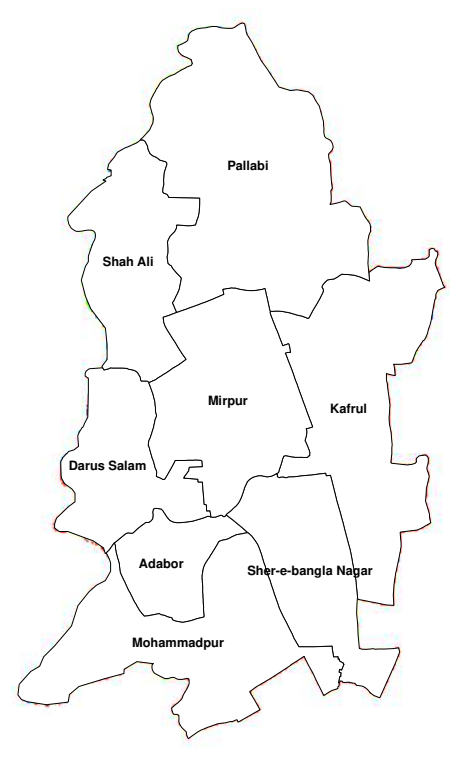

(f) (g)

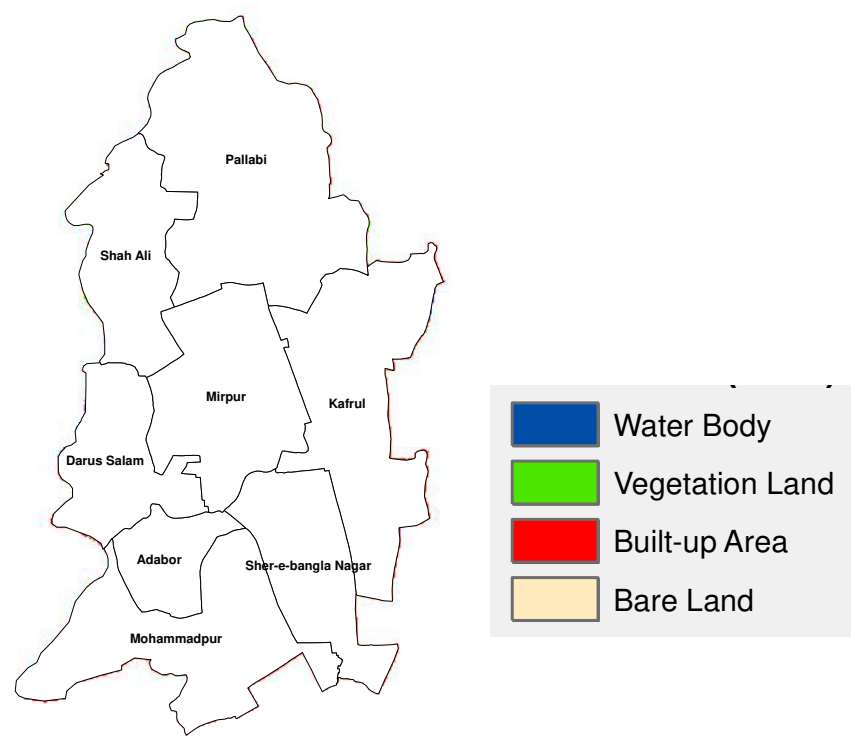

289 Fig. 4: Classified land use land cover map of the study area in (a) 1989, (b) 1994, (c) 1999, (d)

\subsubsection{Percent Change Analysis of Different LULC}

292 During the 1989-2019 study period, LULC categories were converted into other categories and 293 thus losses and gains of LULC categories, were also examined (Table 3). The results indicate that 294 built-up area was generally increasing and water bodies and vegetation land were decreasing 295 significantly during the study period. For the year 1989 to 1994, built up area and bare land area 296 were gained $6.485 \%$ and $4.158 \%$ area, respectively, where vegetation and water bodies were lost 297 by $7.930 \%$ and $2.713 \%$ of its area, respectively. Similar for the year 1994-1999, a significant 298 increase in the built-up area and a very moderate increase in bare land and vegetation area were 299 found and the percentages were showed by $12.717 \%, 1.653 \%$ and $2.056 \%$, respectively. Only 300 dramatic loss in water bodies by $16.445 \%$ was recorded from 1994-1999. Moreover, from 1999301 2004, except built-up area other three LULC classes were facing decreasing trend. Built up area 302 gained by $11.906 \%$ where bare land, water bodies and vegetation land lost $7.686 \%, 3.421 \%$ and 
$3030.789 \%$ area respectively. From 1999, the percentage of built-up area has started to increase

304 because of the conversion of large percentage of bare land to built-up area.

305 Table 3: Percentage Change of LULCs in the Study Area from 1989-2019

\begin{tabular}{cccccccccccccc}
\hline & \multicolumn{1}{c}{ Area in $\mathrm{Km}^{2}$} \\
\cline { 2 - 5 } LULC & 1989 & 1994 & 1999 & 2004 & 2009 & 2014 & 2019 & $1994-$ & $1999-$ & $2004-$ & $2009-$ & $2014-$ & $2019-$ \\
& & & & & & & & 1989 & 1994 & 1999 & 2004 & 2009 & 2014 \\
\hline Water body & 13.4 & 12.03 & 4.00 & 2.33 & 1.69 & 1.34 & 1.13 & -2.713 & -16.445 & -3.421 & -1.305 & -0.715 & -0.440 \\
Urban area & 6.2 & 9.34 & 15.55 & 21.37 & 32.74 & 38.81 & 42.47 & 6.485 & 12.717 & 11.906 & 23.281 & 12.425 & 7.499 \\
Vegetation & 12.2 & 8.32 & 9.33 & 8.95 & 6.88 & 2.56 & 2.37 & -7.930 & 2.075 & -0.789 & -4.228 & -8.863 & -0.380 \\
Bare land & 17.1 & 19.14 & 19.95 & 16.19 & 7.52 & 6.13 & 2.87 & 4.158 & 1.653 & -7.696 & -17.748 & -2.847 & -6.679 \\
Total & 48.83 & 48.83 & 48.83 & 48.83 & 48.83 & 48.83 & 48.83 & & & & & & \\
\hline
\end{tabular}

306 From 2004 to 2009, significantly built-up area gained $23.281 \%$ area where bare land, vegetation 307 and water bodies were reduced to $17.748 \%, 4.228 \%$ and $1.305 \%$ respectively. From 2009 to

3082014 , built up area gained by $12.425 \%$ whereas bare land, vegetation and water bodies reduced to $3092.847 \%, 8.863 \%$ and $0.715 \%$ respectively. Considering the year 2014-2019, built up area gained 310 by $7.499 \%$ whereas bare land, vegetation and water bodies were reduced to $6.679 \%, 0.383 \%$ and $3110.440 \%$ respectively. Overall, the highest losses (bare land and vegetation) and gains (urban area) 312 were observed in the 2004-2014 period. However, the water body expansively was lost its 313 coverage from 1994 to 1999 (Table 3).

\section{3.1.2 Field validation of LULC}

315 Table 4 demonstrates the classification of overall accuracy, Kappa coefficient, and validation of 316 land use classification. For the year 2019, the overall accuracy was over $90 \%$ and the result of the 317 Kappa coefficient was 0.83 . The accuracy level is classified as very strong when the Kappa 318 coefficient is greater than 0.75 (Congalton \& Green, 2008; Foody, 2002; Pontius Jr \& Millones, 3192011 ; Story \& Congalton, 1986). In order to validate the land use classification, 50 sampling points 320 were compared with the corresponding point on Google Earth images over the same period. In 321 conclusion, the overall classification accuracy, Kappa coefficient statistics, and validation all show 322 good accuracy which is suitable for LULC simulation. 
Table 4: Accuracy Assessment for 2019 LULC

\begin{tabular}{ccccccc}
\hline \multicolumn{7}{c}{ Ground Truth } \\
\hline Classified Class & $\begin{array}{c}\text { Water } \\
\text { body }\end{array}$ & Urban & Vegetation & Bare Land & Total & $\begin{array}{c}\text { User } \\
\text { Accuracy }\end{array}$ \\
\hline Water & 10 & 0 & 1 & 0 & 11 & 90.91 \\
Built up Area & 0 & 15 & 0 & 1 & 16 & 93.75 \\
Vegetation & 0 & 0 & 11 & 1 & 12 & 91.67 \\
Bare Land & 1 & 1 & 0 & 9 & 11 & 81.82 \\
Total & 11 & 16 & 12 & 11 & 50 & \\
Producer & & & & & Overall & Kappa \\
Accuracy & 90.91 & 93.75 & 91.67 & 81.82 & Accuracy & Statistics \\
& & & & & 90 & 83.85 \\
\hline
\end{tabular}

$325 \quad 3.2$ Estimation of Land Surface Temperature (LST)

326 Fig. (5a to $5 \mathrm{~g}$ ) indicates the spatial pattern of LST distribution. In all maps bright yellow tone

327 represents higher temperature and greenish tone represents low surface temperature. LST 328 concentration and spatial and temporal LST patterns display rapid changes in LULC groups. The 329 core built-up area is sensitive to high temperatures. As the images were taken in the month of 330 November which is generally winter season in Bangladesh, therefore, displayed data will show the 331 temperature of corresponding winter season of the years.

332 Fig. (5a and 5b) focuses on annual surface temperature conditions of 1989 and 1994 and LST 333 varied within the range of less than $20-24^{\circ} \mathrm{C}$. From 1999 and 2004 temperature decreased slightly 334 and the reason is Bangladesh went under massive flood during that period. 
(a)

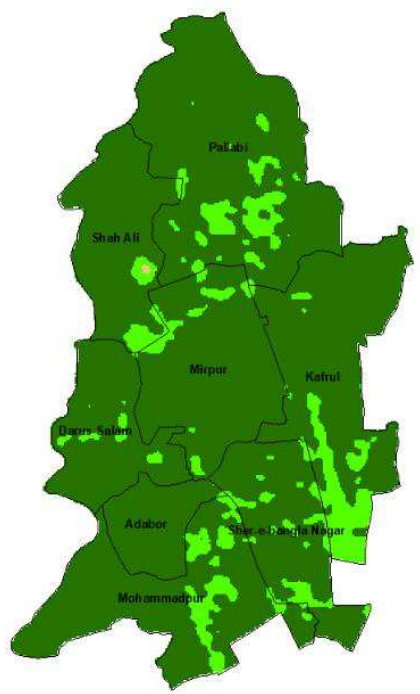

(e)

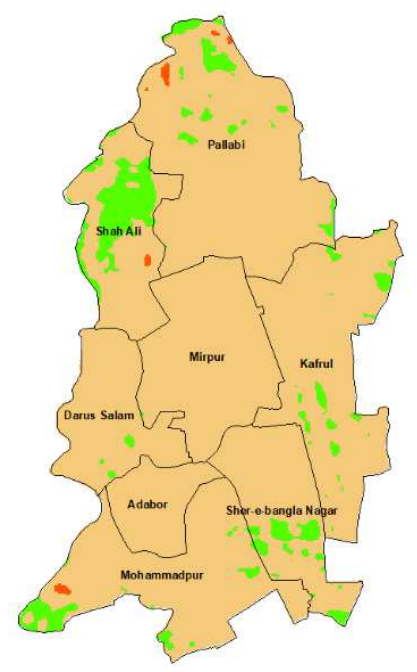

(b)

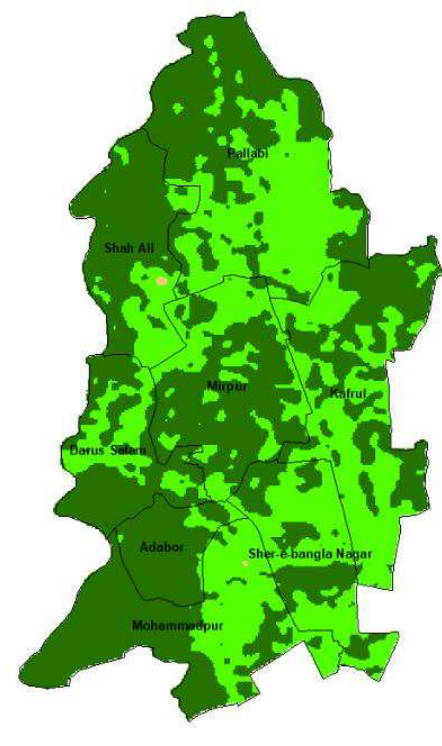

(f)

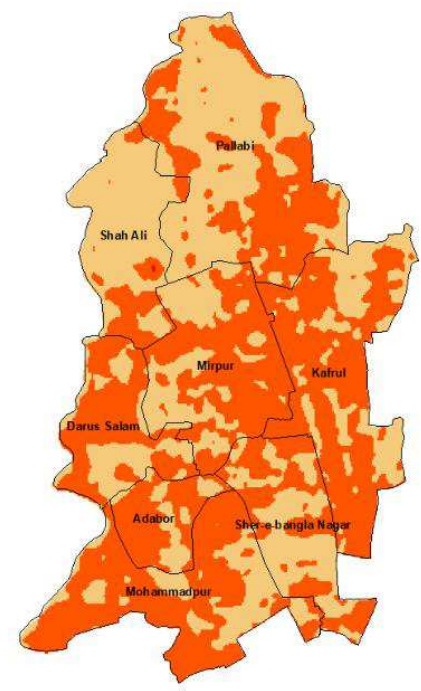

(c)

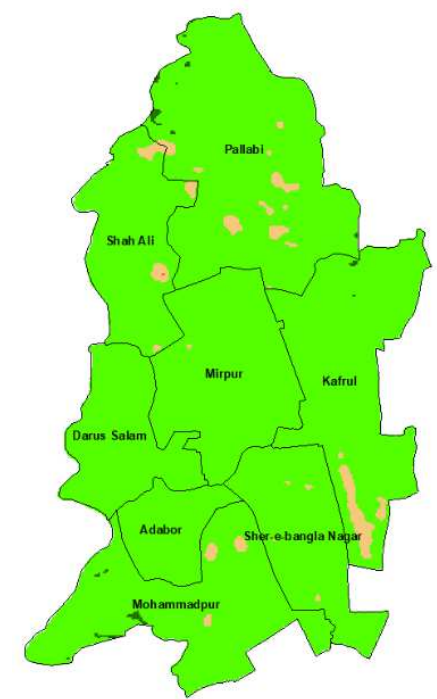

(g)

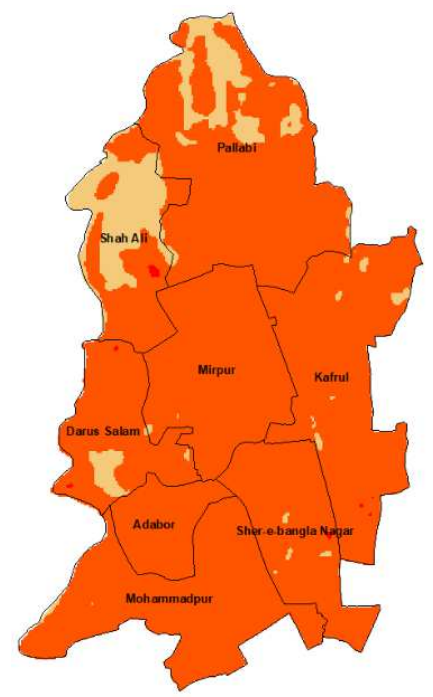

(d)
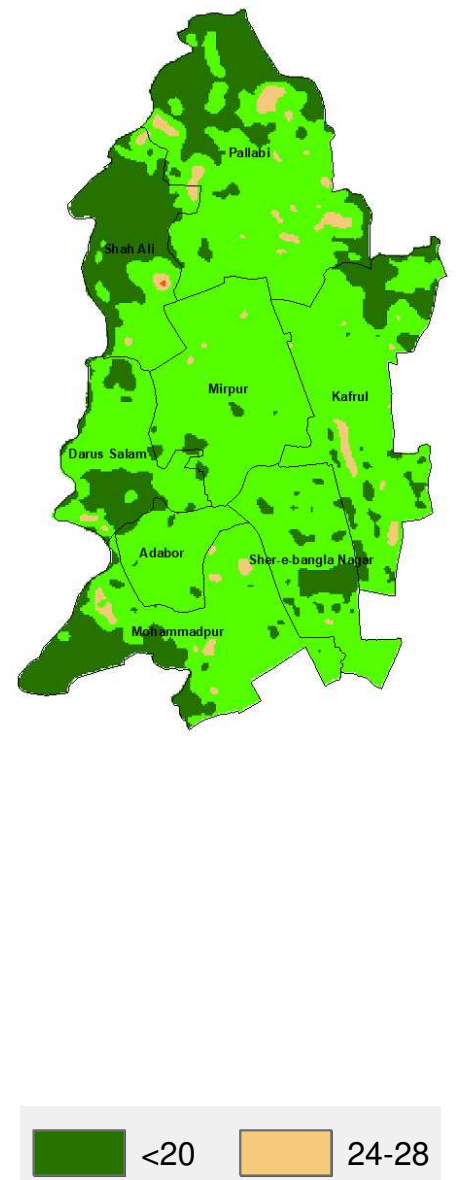

20-24

28-32

335 Fig. 5: Land surface temperature distribution in the year (a) 1989, (b) 1994, (c) 1999, (d)

337 In that period, surface water existed for a long period. For that temperature was comparatively

338 lower than the previous year and LST varied $20-32^{\circ} \mathrm{C}$ (Fig. 5c and 5d). In the year of 2009 the

339 LST varied $20-32^{\circ} \mathrm{C}$ (Fig. 5d). For 2014 and 2019, the LST were found at the highest peak

340 because of the significant increase of built-up area and reduction of water bodies and vegetation

341 land. From 2014 to 2019 , LST varied from $24^{\circ} \mathrm{C}$ to more than $34^{\circ} \mathrm{C}$ (Fig. 5e to $5 \mathrm{~g}$ ). The north- 
342 western part of the study area exhibited lowering in temperature due to higher vegetation and

343 agricultural land whereas the south eastern part exhibits the rise in LST due to rapid urban

344 expansion and declining of water bodies as well as vegetation land.

\section{$345 \quad 3.2 .1$ Percent Change in LST}

346 The Percent Change in LST will provide a better insight about the temperature variation at different

347 ranges of LST. From 1989 to 1994, the highest percentage of area (30.946\%) was lost in having

348 LST below $20^{\circ} \mathrm{C}$ range. Also, $30.928 \%$ area increased within the range of $20-24^{0} \mathrm{C}$. Due to

349 abundance of vegetation and water bodies, temperature range above $28^{\circ} \mathrm{C}$ found unavailable (Table

350 5). From 1989 to 1994, the highest percentage of area (57.063\%) was lost in having LST below

$35120^{\circ} \mathrm{C}$ range. Also, $54.829 \%$ area increased within the range of $20-24^{\circ} \mathrm{C}$. Due to abundance of

352 vegetation and water bodies, temperature range above $32^{\circ} \mathrm{C}$ found unavailable (Table 5).

353 Due to heavy flood in 2004, LST reduced to less than $20^{\circ} \mathrm{C}$ from 1999 to 2004 (Table 5). But, from

354 the year 2004 to 2009, maximum percentage of area increased to $89.09 \%$ within the LST range of

$35524-28^{\circ} \mathrm{C}$. During this period significant increase of built-up area, reduction of water bodies and

356 vegetation area were noticed (Table 3).

357 Table 5: Percentage Change of LSTs in the Study Area from 1989-2019 $\left(\mathrm{km}^{2}\right)$

\begin{tabular}{|c|c|c|c|c|c|c|c|c|c|c|c|c|c|}
\hline \multirow{2}{*}{$\begin{array}{l}\text { LST } \\
\text { Range }\end{array}$} & \multicolumn{7}{|c|}{ Area in $\mathrm{Km}^{2}$} & \multicolumn{6}{|c|}{ Change in $\%$} \\
\hline & 1989 & 1994 & 1999 & 2004 & 2009 & 2014 & 2019 & $\begin{array}{c}1994- \\
1989\end{array}$ & $\begin{array}{c}1999- \\
1994\end{array}$ & $\begin{array}{c}2004- \\
1999\end{array}$ & $\begin{array}{c}2009- \\
2004\end{array}$ & $\begin{array}{c}2014- \\
2009\end{array}$ & $\begin{array}{l}2019- \\
2014\end{array}$ \\
\hline$<20^{\circ} \mathrm{C}$ & 43.11 & 28 & 0.13 & 12.01 & 0 & 0 & 0 & -30.95 & -57.06 & 24.33 & -24.60 & 0 & 0 \\
\hline $20-24^{\circ} \mathrm{C}$ & 5.02 & 20.12 & 46.89 & 34.93 & 3.30 & 0 & 0 & 30.93 & 54.83 & -24.51 & -64.76 & -6.76 & 0 \\
\hline $24-28^{\circ} \mathrm{C}$ & 0.70 & 0.71 & 1.12 & 1.20 & 44.71 & 21.93 & 4.46 & 0.02 & 0.83 & 0.17 & 89.10 & -46.65 & -35.78 \\
\hline $28-32^{\circ} \mathrm{C}$ & 0 & 0 & 0.69 & 0.69 & 0.82 & 26.28 & 43.64 & 0 & 1.41 & 0.009 & 0.27 & 52.14 & 35.55 \\
\hline$>32^{\circ} \mathrm{C}$ & 0 & 0 & 0 & 0 & 0 & 0.62 & 0.74 & 0 & 0 & 0 & 0 & 1.27 & 0.24 \\
\hline Total & 48.83 & 48.83 & 48.83 & 48.83 & 48.83 & 48.83 & 48.83 & & & & & & \\
\hline
\end{tabular}

358 Built-up area continued to increase from 2009 to 2014 and from 2014 to 2019 (Table 3) which

359 resulted in the increase of LST more than $32^{\circ} \mathrm{C}$. Maximum area of temperature found within 28-

$36032^{\circ} \mathrm{C}(35.784 \%$ area $)$ and it was $52.136 \%$ area in 2009 to 2014 . Here, $1.273 \%$ and $0.238 \%$ area

361 increased to more than $32^{\circ} \mathrm{C}$ from the year 2009 to 2014 . The increase of built-up area, reduction 
362 of water bodies and vegetation land were dominant from the year 2009 which contributed to

363 increase of LST more than $32^{\circ} \mathrm{C}$ from 2009.

365 As the simulation of future LST pattern was estimated on the basis of 1989 to 2019 data at 5 years

366 interval period and BMD Agargaon station's data was available from 2013 to 2018 therefore only

367 LST data of 2014 could be validated. Estimated LST data has minimum and maximum LST value

368 and BMD data also had minimum and maximum temperature data. Therefore, the percentage of

369 error was calculated in two ways considering maximum and minimum LST and temperature

370 values. After validating both source data, the minimum and maximum temperature error was

371 estimated as $3.678 \%$ and $4.982 \%$, respectively. The percentage of error was negligible and

372 therefore the estimation of LST was acceptable for further processing by considering a little

373 limitation (Table 6).

374 Table 6: Validation of LST simulation based to the estimate LST for the year 2014

\begin{tabular}{|c|c|c|c|}
\hline Year & $\begin{array}{l}\text { Temperature from Satellite } \\
\text { Image }\end{array}$ & BMD Data & Percentage of Error \\
\hline \multirow{4}{*}{2014} & \multicolumn{3}{|c|}{ Minimum Temperature } \\
\hline & 24.883 & 24.000 & 3.678 \\
\hline & \multicolumn{3}{|c|}{ Maximum Temperature } \\
\hline & 32.545 & 31.000 & 4.982 \\
\hline
\end{tabular}

377 The most effective method for determining the effect of LULC on LST is to study the relationships 378 between thermal signatures and land cover types. The radiative radiation radiated from the 379 ground's surface, including roofs, pavements, plants, bare soil, and water bodies, was measured 380 and stored as LST using remotely sensed sensors. Two cross-sections were taken over the research 381 region to represent the LST for each LULC type, and the average LST for each LULC type is 
382 presented in Fig. 6. (a-g). Two cross-sections were investigated, one from northwest to southeast 383 ( $\mathrm{AB})$ and one from northeast to southwest (CD).

384 From the profile, it was found that congested built-up area experienced average LST more than $38524^{\circ} \mathrm{C}$ in 1989 (Fig. 6a), $>27^{\circ} \mathrm{C}$ in 1994 (Fig. 6b), > $28^{\circ} \mathrm{C}$ in 1999 (Fig. 6c), $29^{\circ} \mathrm{C}$ in 2004 (Fig. 386 6d), $>30^{\circ} \mathrm{C}$ in 2009 (Fig. 6e), $>32^{\circ} \mathrm{C}$ in 2014 (Fig. 6f) and $>34^{\circ} \mathrm{C}$ in 2019 (Fig. 6g). Also, highest 387 LST was recorded as $22^{\circ} \mathrm{C}$ in $1989,>25^{\circ} \mathrm{C}$ in $1994,>27^{\circ} \mathrm{C}$ in $1999,28^{\circ} \mathrm{C}$ in $2004,>30^{\circ} \mathrm{C}$ in $3882009,>31^{\circ} \mathrm{C}$ in 2014 and $>33^{\circ} \mathrm{C}$ in 2019 for bare land in seven different years' cross-sections.

389 Besides, other two LULC (water bodies and vegetation) were recorded as the lowest temperature 390 ranging from $16^{\circ} \mathrm{C}$ to $27^{\circ} \mathrm{C}$. The findings signify that built-up area increases LST by replacing 391 natural vegetation with non-evaporating and non-transpiring surfaces.

(a)

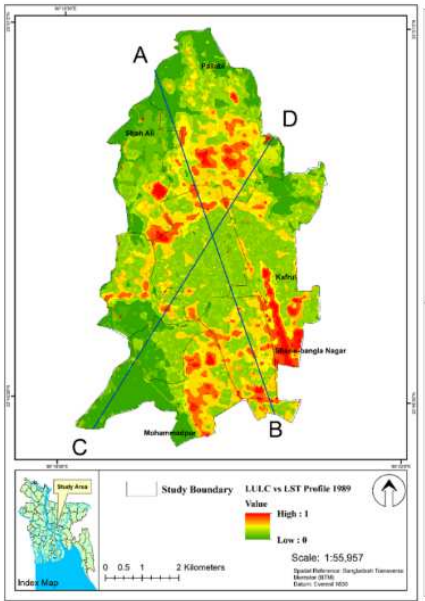

(c)

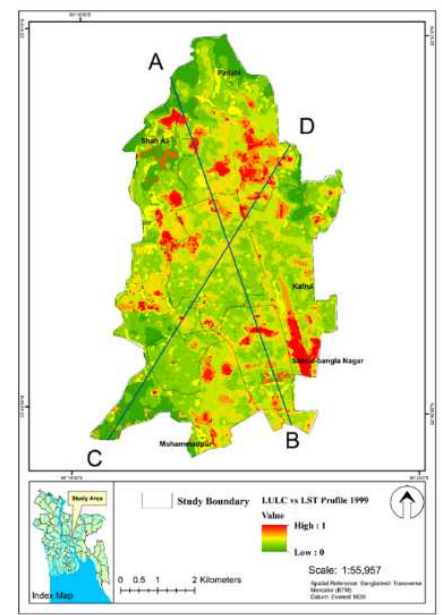

(b)
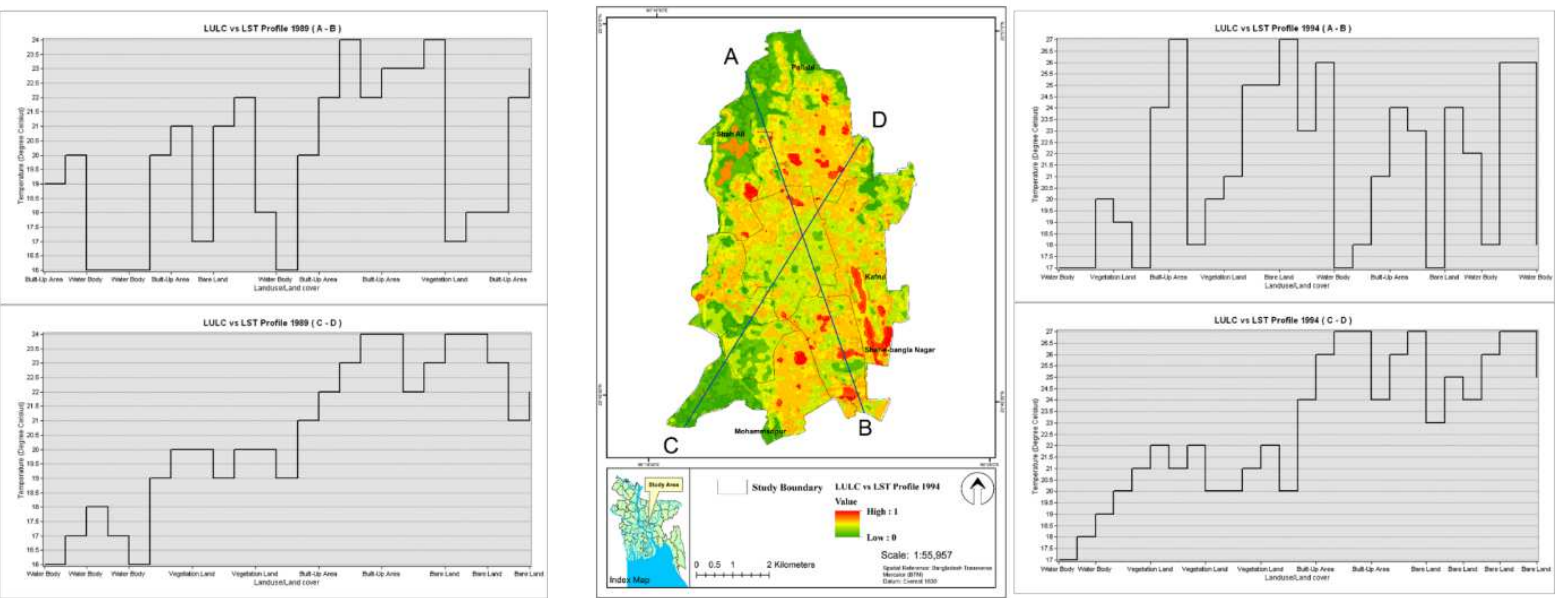

(d)

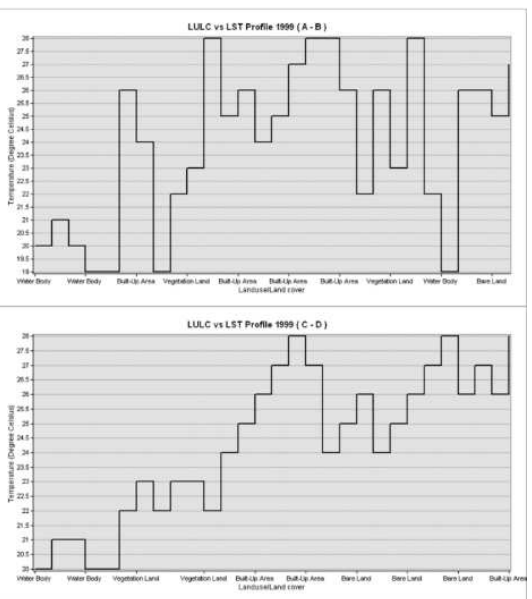

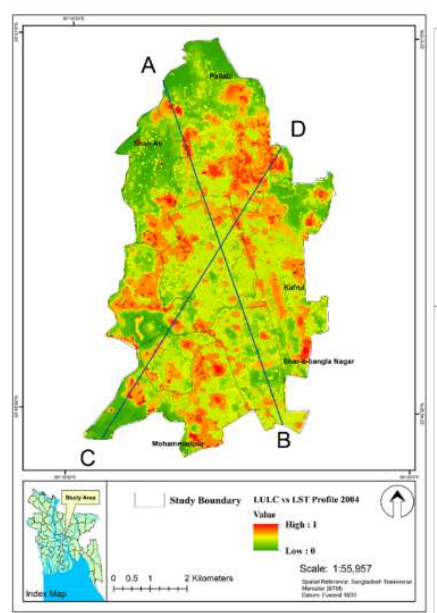

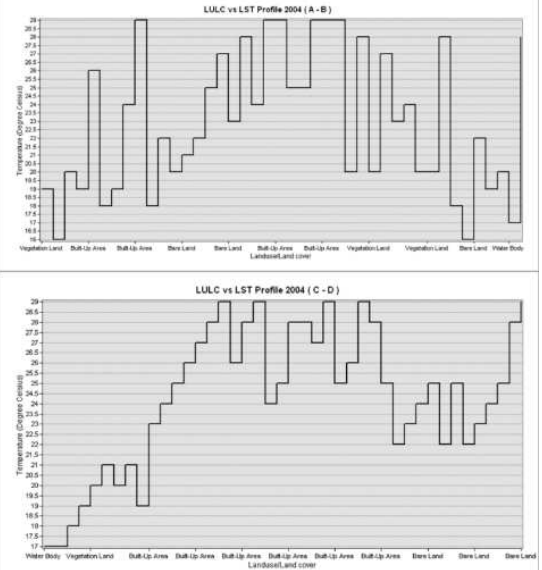


(e)
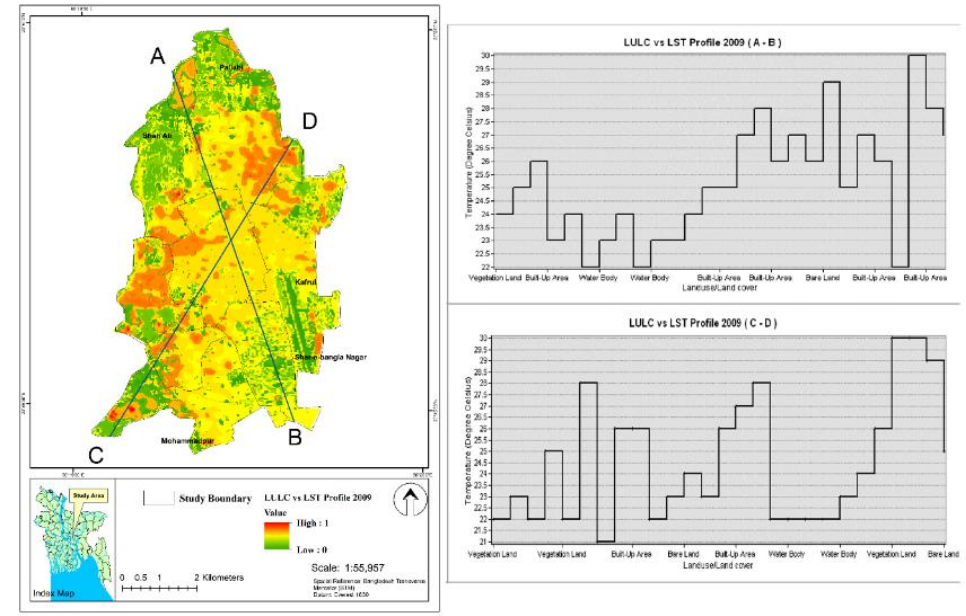

(g)
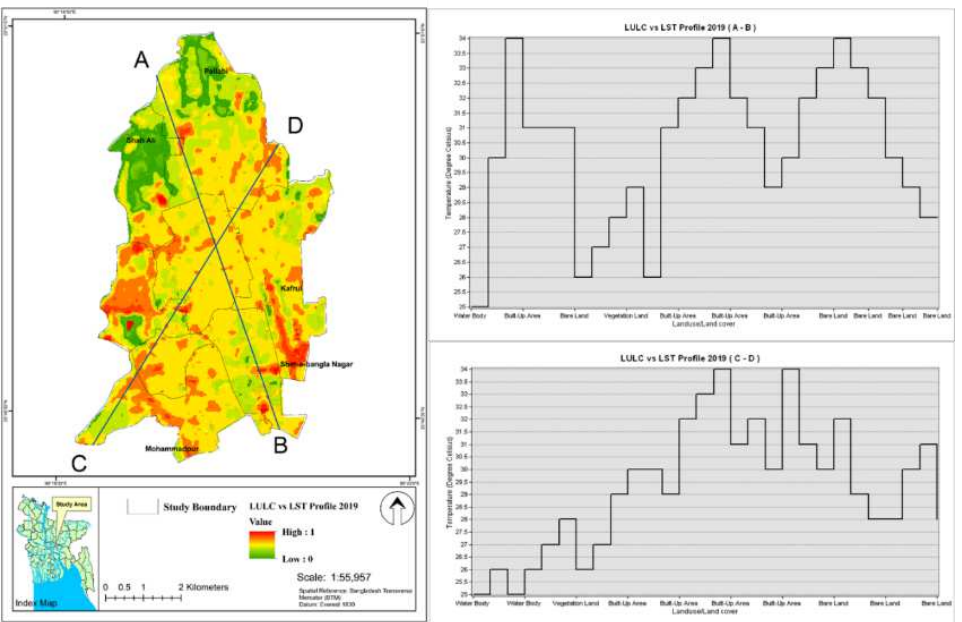

(f)
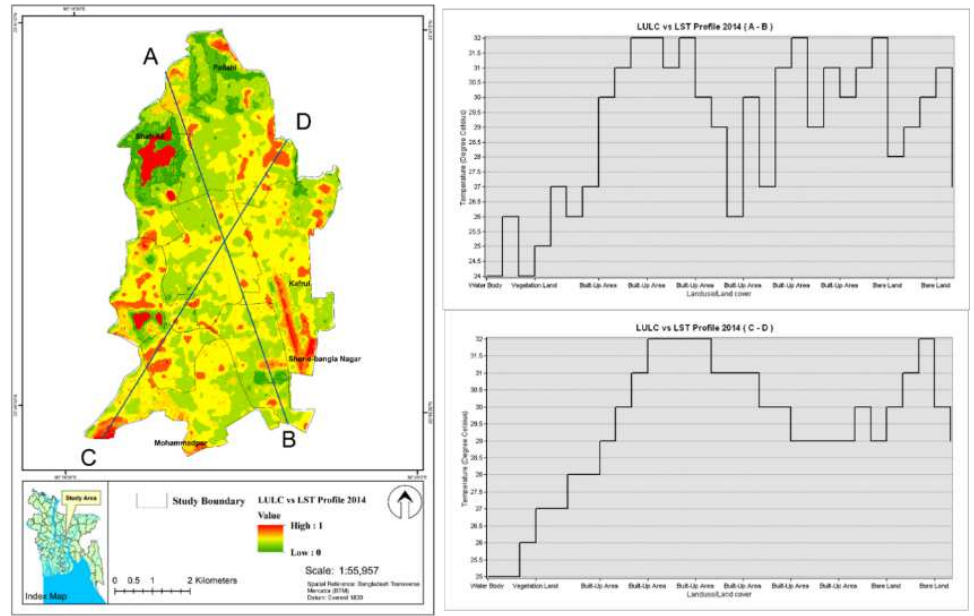

392 Fig. 6: Cross Sectional Profile of LULC vs LST for the Year (a) 1989, (b) 1994, (c) 1999, (d)

393 2004, (e) 2009, (f) 2014 and (g) 2019

395 The distribution of LST in different LULC classes in various ranges demonstrates the LULC wise 396 LST concentration in the study area. Considering the LST distribution in different LULC classes 397 for the year 1989, most of the area was experienced below $20^{\circ} \mathrm{C}$ in every LULC class and the 398 covered area under $20^{\circ} \mathrm{C}$ was $15.40 \mathrm{sq} . \mathrm{km}$ in water bodies, $12.27 \mathrm{sq}$. km in bare land, $3.24 \mathrm{sq} . \mathrm{km}$ 399 in built-up area and 12.20 sq. $\mathrm{km}$ in vegetation cover (Table 7). In 1994 most of the area 400 experienced below $20^{\circ} \mathrm{C}$ for all LULC and the dominated LULC was bare land (14.08 sq. km), 
401 water bodies (10.35 sq. km), and vegetation (2.91 sq. km). At LST range 20-240 C, 7.97 sq. km, 4025.41 sq. km and 5.06 sq. km area were recorded as built-up area, vegetation land and bare land 403 respectively (Table 7).

404 For the year 1999 , the highest range was $20-24^{\circ} \mathrm{C}$ and the maximum coverage of LULC class was 405 bare land (19.11 sq. km), followed by built-up area (15.75 sq. km) and vegetation land (5.30 sq. $406 \mathrm{~km})$ (Table 7).

407 Table 7: LULC Wise LST Distribution from 1989 to 2019

\begin{tabular}{|c|c|c|c|c|c|}
\hline Temperature & $<20^{\circ} \mathrm{C}$ & $20-24^{0} \mathrm{C}$ & $24-28^{0} \mathrm{C}$ & $28-32^{0} \mathrm{C}$ & $>32^{\circ} \mathrm{C}$ \\
\hline Land cover & \multicolumn{5}{|c|}{1989 (area in $\mathrm{km}^{2}$ ) } \\
\hline Water Body & 15.40 & 0.00 & - & - & - \\
\hline Built-Up Area & 3.24 & 2.89 & 0.70 & - & - \\
\hline Vegetation Land & 12.20 & 0.00 & - & - & - \\
\hline Bare Land & 12.27 & 2.12 & - & - & - \\
\hline Landover & \multicolumn{5}{|c|}{1994} \\
\hline Water Body & 10.35 & 1.68 & - & - & - \\
\hline Built-Up Area & 0.66 & 7.97 & 0.71 & - & - \\
\hline Vegetation Land & 2.91 & 5.41 & - & - & - \\
\hline Bare Land & 14.08 & 5.06 & & - & - \\
\hline Landover & \multicolumn{5}{|c|}{1999} \\
\hline Water Body & 0.09 & 3.91 & 0.00 & 0.00 & - \\
\hline Built-Up Area & 0.00 & 14.54 & 0.32 & 0.69 & - \\
\hline Vegetation Land & 0.04 & 9.33 & 0.00 & 0.00 & - \\
\hline Bare Land & 0.00 & 19.11 & 0.84 & 0.00 & - \\
\hline Land cover & \multicolumn{5}{|c|}{2004} \\
\hline Water Body & 1.42 & 0.39 & 0.00 & 0.00 & - \\
\hline Built-Up Area & 1.94 & 18.05 & 1.20 & 0.69 & - \\
\hline Vegetation Land & 4.59 & 4.36 & 0.00 & 0.00 & - \\
\hline Bare Land & 4.06 & 12.13 & 0.00 & 0.00 & - \\
\hline Land cover & \multicolumn{5}{|c|}{2009} \\
\hline
\end{tabular}




\begin{tabular}{cccccc}
\hline Temperature & $\mathbf{2 0}^{\mathbf{0}} \mathbf{C}$ & $\mathbf{2 0 - 2 4}^{\mathbf{0}} \mathbf{C}$ & $\mathbf{2 4 - 2 8}^{\mathbf{C}} \mathbf{C}$ & $\mathbf{2 8 - 3 2}^{\mathbf{0}} \mathbf{C}$ & $\mathbf{3 2}^{\mathbf{0}} \mathbf{C}$ \\
\hline Water Body & - & 1.32 & 0.37 & 0 & - \\
Built-Up Area & - & 0.02 & 31.90 & 0.82 & - \\
Vegetation Land & - & 1.45 & 5.43 & 0 & - \\
Bare Land & - & 0.51 & 6.75 & 0 & - \\
Land cover & - & & $\mathbf{2 0 1 4}$ & & 0.00 \\
Water Body & - & - & 1.33 & 0.01 & 0.59 \\
Built-Up Area & - & - & 15.18 & 23.04 & 0.00 \\
Vegetation Land & - & - & 1.23 & 1.33 & 0.03 \\
Bare Land & - & - & 4.19 & 1.89 & \\
Land cover & & - & $\mathbf{2 0 1 9}$ & & 0.00 \\
Water Body & - & - & 0.92 & 0.21 & 0.61 \\
Built-Up Area & - & - & 0.92 & 40.94 & 0.00 \\
Vegetation Land & - & - & 1.84 & 0.53 & 0.14 \\
Bare Land & - & - & 0.78 & 1.95 &
\end{tabular}

408 In 2004, the highest range of LST was $20-24^{\circ} \mathrm{C}$ and the maximum LULC classes were built-up 409 area (18.05 sq. km), followed by bare land area (12.13 sq. km). The lowest LST found at water 410 bodies (1.42 sq. $\mathrm{km}$ ) which was below $20^{\circ} \mathrm{C}$ (Table 7). In year 2009, the highest range of 411 temperature was $24-28^{\circ} \mathrm{C}$ and the maximum coverage of LULC class was in urban area (31.90 sq. $412 \mathrm{~km})$, followed by bare land area $(6.75 \mathrm{sq} . \mathrm{km})$. The lowest temperature was recorded urban area 413 (0.02 sq. km) under $20-24^{0} \mathrm{C}$ temperature (Table 7$)$.

414 As the built-up area is continuously increasing, therefore, LST values got a momentum from 2014 415 to 2019 . In 2014 , highest percentage of built-up areas were found in the range of $28-32^{\circ} \mathrm{C}$ and 24 $41628^{0} \mathrm{C}$ with corresponding areas of 23.04 sq. $\mathrm{km}$ and 15.15 sq. km respectively. In $2019,0.61$ sq. $417 \mathrm{~km}$ and $40.94 \mathrm{sq} . \mathrm{km}$ of built-up areas were found having more than $32^{\circ} \mathrm{C}$ and $28-32^{\circ} \mathrm{C}$ respectively 418 (Table 7).

419 3.4 Relationship among LST, NDVI and NDBI

420 Two land cover indices, the NDVI and the NDBI, were developed in order to quantify the link 421 between LST and the indices. The lower NDVI value was associated with a greater LST level in 
422 this study. Additionally, the NDVI score in the studied region decreased from -0.1 to -0.3 between 4231989 and 2019. The lower NDVI value corresponds to paved ground, bare soil, and rock, all of 424 which result in elevated surface temperatures. Low NDVI values (0.2 to 0.3) correspond to shrub 425 and grassland, whereas high values correspond to green surfaces.

426 On the contrary, the NDBI value increased steadily, resulting in greater LST levels. From 1989 to 427 2019, the results of linear regression and multiple correlation reveal that LST has a significant and 428 positive connection with NDBI and a strong and negative correlation with NDVI (Fig. 7a to 7g). 429 In all correlation analyses, the $\mathrm{R} 2$ value was greater than 0.75 , indicating that the variables were 430 highly linked. By entering the value of an independent variable such as LST for each year, the 431 resulting linear regression formula developed an equation for forecasting the dependent variable 432 NDVI or NDBI. The equation fluctuates year to year and may be used to model more complex 433 relationships between LST, NDBI, and NDVI. Additionally, the correlation coefficient for each 434 equation with a complicated relationship between variables may be addressed in greater detail in 435 future research (Figure $7 \mathrm{a}-7 \mathrm{~g}$ ).

(a)

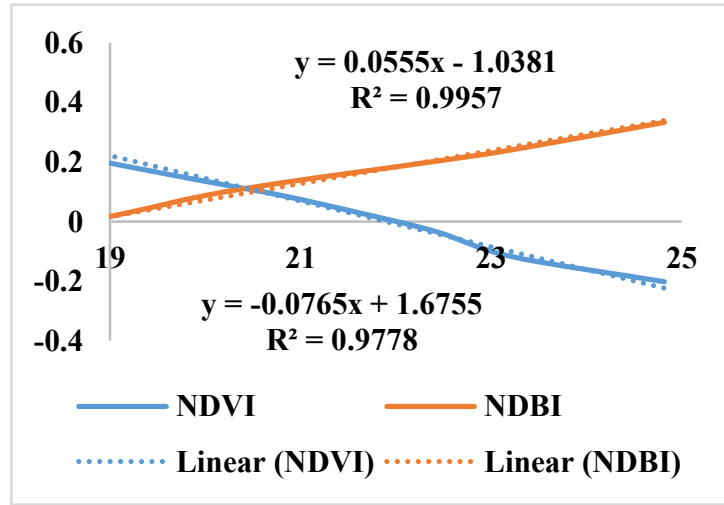

(b)

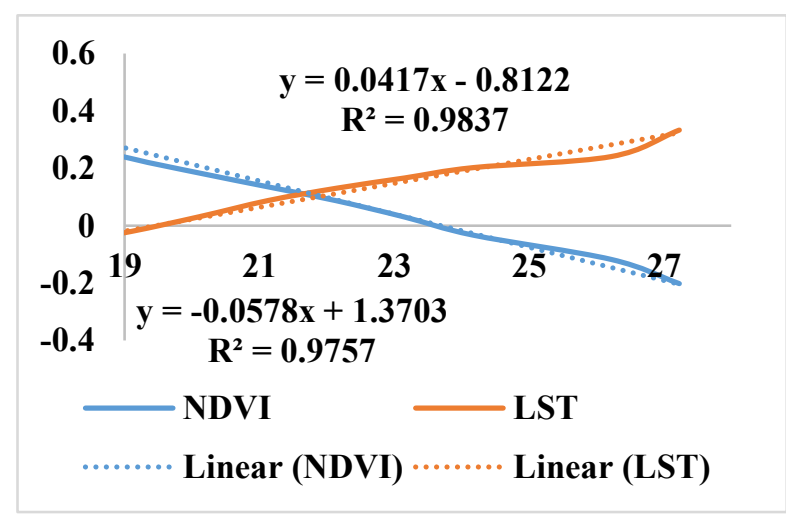


(c)

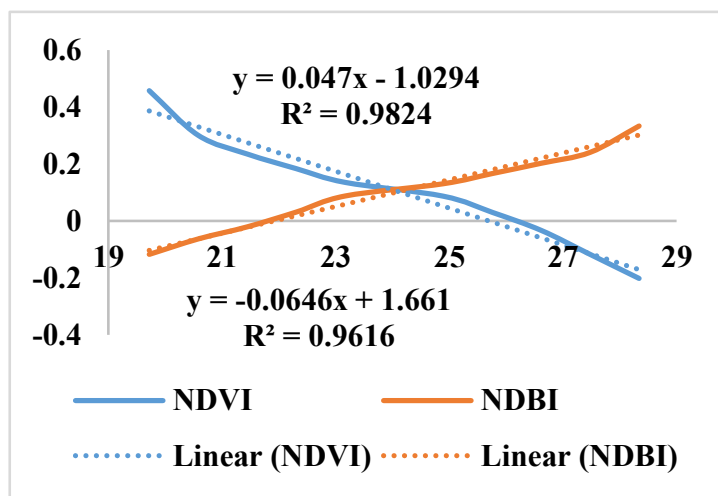

(e)

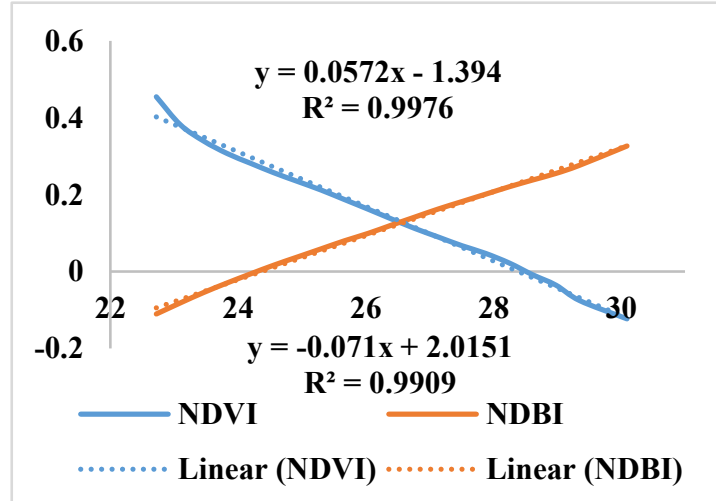

(g)

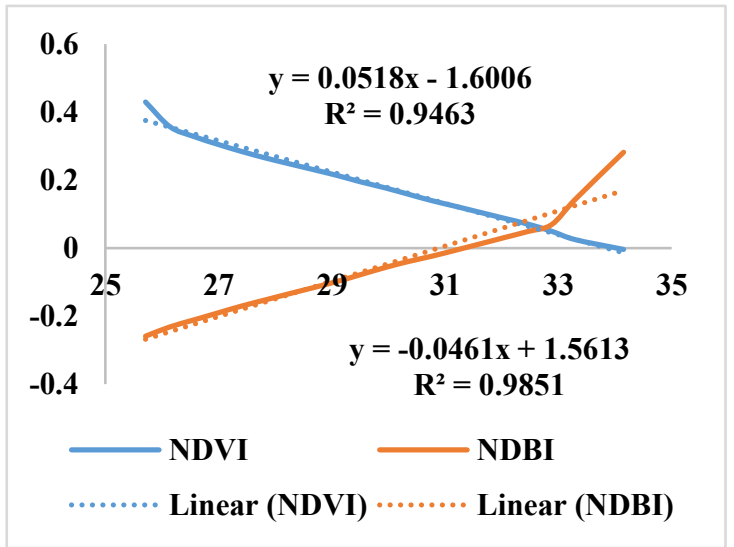

(d)

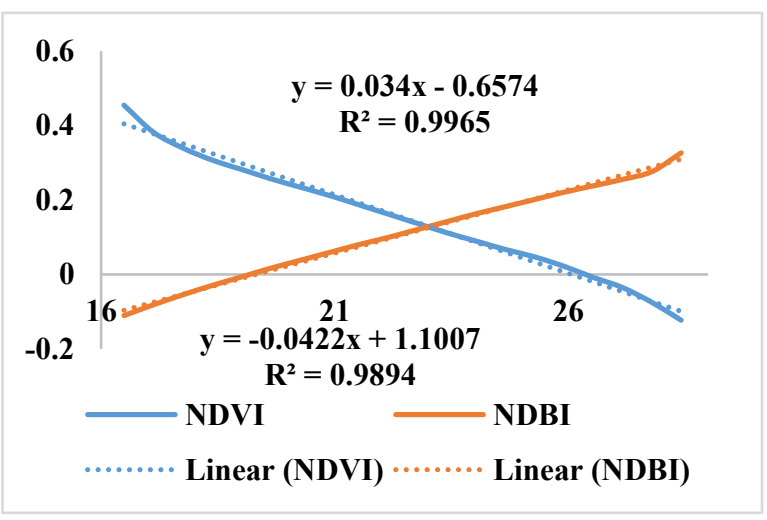

(f)

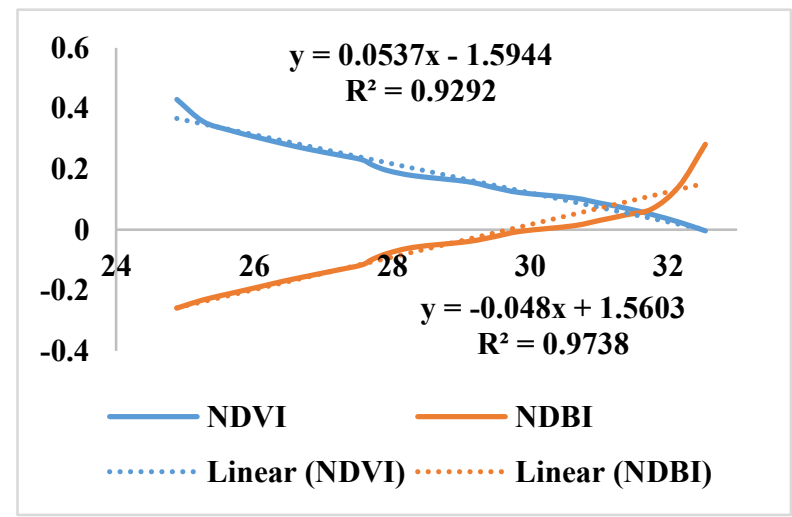

436 Fig. 7: Correlation between LST vs NDVI \& NDBI in the year (a) 1989, (b) 1994, (c) 1999,

(d) 2004, (e) 2009, (f) 2014 and (g) 2019 
439 LULC classes in the research region changed considerably throughout the study period (1989440 2019). It was necessary to predict future LULC dynamics because, if historical trends continue, 441 LST would change, affecting both biodiversity and microclimate in the research region. 442 Additionally, the future LULC forecast is critical because it establishes a foundation for 443 sustainable urban design. Additionally, the variance in LST analysis from 1999 to 2019 444 demonstrated a noticeable shift. As a result, it was critical to forecast future LST trends. The CA445 ANN model was used to forecast future LULC and LST for the year 2039 by analyzing the research 446 area's historical LULC and LST trends. The prediction's accuracy was confirmed using the 447 proportion of right predictions, the overall Kappa value, the Kappa location value, and the Kappa 448 history value for the predicted variables. The model validation findings for transition potential 449 modeling indicated that the total Kappa index and percent-correctness value were 84 percent 450 (Table 8), which is an acceptable degree of accuracy for LULC modeling. The model validation 451 result shown in Figure 8a was obtained using the QGIS program.

Table 8: ANN Model Validation for LULC in QGIS MOLUSCE Plugin

\begin{tabular}{ccccc}
\hline Prediction Year & \multicolumn{4}{c}{ ANN model validation for LULC prediction } \\
\hline \multirow{3}{*}{2039} & \multicolumn{4}{c}{ QGIS-MOLUSCE Plugin module } \\
\cline { 2 - 5 } & \%-correctness & Overall Kappa Value & Kappa- location & Kappa- histo \\
\cline { 2 - 5 } & $84.56 \%$ & 0.84508 & 0.8529 & 0.8852 \\
\hline
\end{tabular}

453 Simulation results showed that approximately $92 \%$ of the area will be converted into built-up area 454 in 2039 (Fig. 8b). Predicted LULC change in future could adversely affect the environment altering 455 both climate and biodiversity of the area. 
(a)

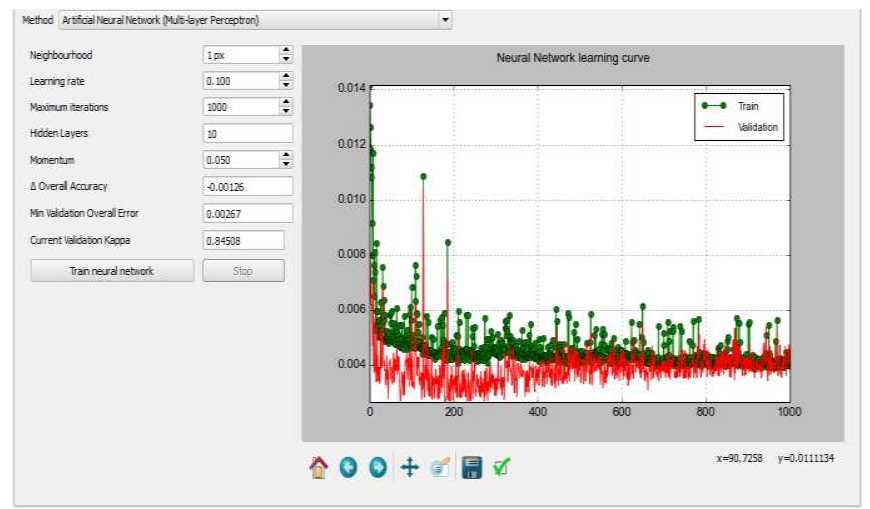

(b)

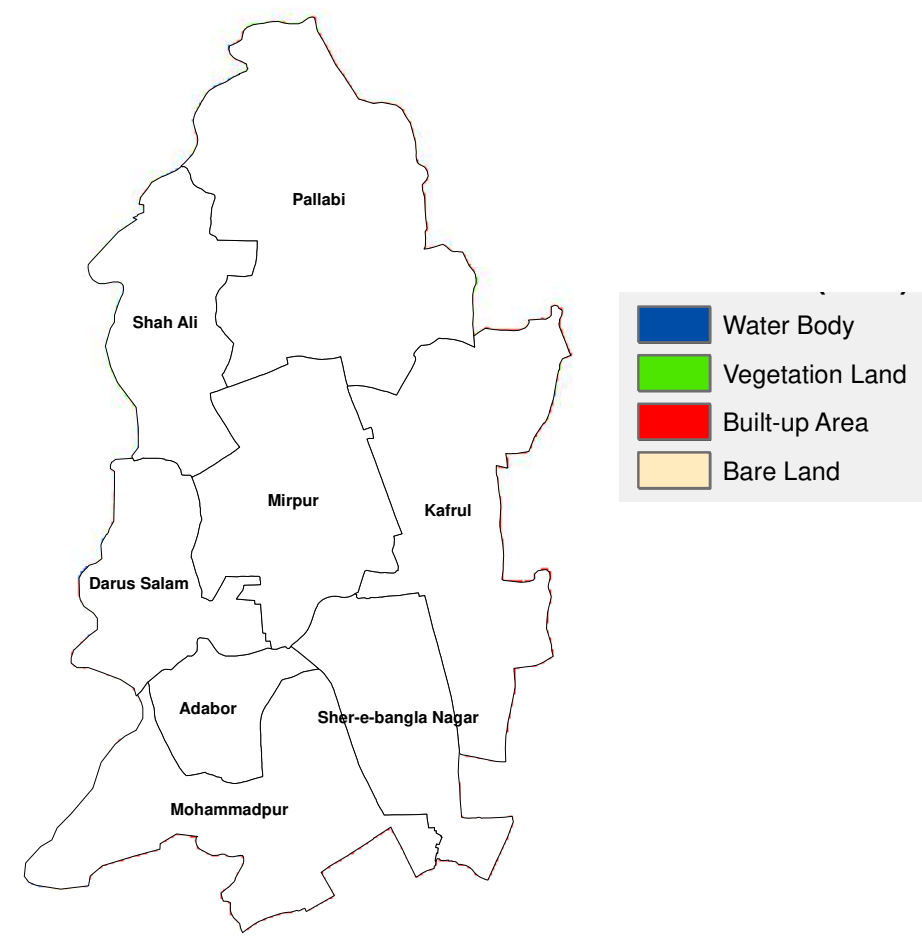

457 458

459

Table 9: Percentage Change of LULCs in the Study Area from 2019-2039

\begin{tabular}{cccccc}
\hline LULC & $\begin{array}{c}\text { Area } \mathrm{km}^{2} \\
(2019)\end{array}$ & Area in \% & Area km $^{2}(2039)$ & Area in \% & $\begin{array}{c}\text { Change in \% } \\
(2039-2019)\end{array}$ \\
\hline Water body & 1.1259 & 2.31 & 1.12 & 2.29 & -0.012 \\
Built up area & 42.4674 & 86.96 & 45.13 & 92.42 & 5.459 \\
Vegetation & 2.3697 & 4.85 & 2.05 & 4.19 & -0.664 \\
Bare land & 2.871 & 5.88 & 0.53 & 1.09 & -4.788 \\
Total & 48.83 & 100.00 & 48.83 & 100.00 & \\
\hline
\end{tabular}

460 The percentage of change indicates that in 2039, built-up area would increase about $5.5 \%$ higher 461 than the 2019 if this pattern continues. Moreover 92.42\% of Mirpur and surrounding area would 462 convert in to built-up area and there will be drastic reduction of other LULC such as vegetation, 463 bare land and water bodies (Table 9). 
465 The simulated result showed a strong agreement that confirmed the accuracy of the ANN model's 466 prediction for 2039 with $91.856 \%$ correctness and 0.9362 overall Kappa value (Table 10). Based 467 on the ANN model validation in other researches, the percentage of correctness value over $80 \%$ 468 demonstrates strong agreement of accuracy.

469 Table 10: ANN Model Validation for LST in QGIS MOLUSCE Plugin

\begin{tabular}{ccccc}
\hline Prediction Year & \multicolumn{4}{c}{ ANN model validation for LST prediction } \\
\hline \multirow{3}{*}{2039} & \multicolumn{4}{c}{ QGIS-MOLUSCE Plugin module } \\
\cline { 2 - 5 } & \%-correctness & Overall Kappa Value & Kappa- location & Kappa- histo \\
\cline { 2 - 5 } & 91.856 & 0.9362 & 0.9037 & 0.92582 \\
\hline
\end{tabular}

470 The validation provided an excellent accuracy with more than $90 \%$ of correctness for simulated 471 LST map in 2039 (Fig. 9a). Similar to the LULC for the study period from 1989-2019, LST also 472 shows a substantial amount of change. Accordingly, LST is simulated for 2039. The past trends of 473 estimated LST data are used in the ANN model to predict the future LST trends of the study area.

474 The prediction exhibited that approximately $23.69 \%$ of Mirpur area likely to have LST greater 475 than $32^{\circ} \mathrm{C}$ and $72.62 \%$ area is likely to remain $28-32^{\circ} \mathrm{C}$ LST range. There may not be any 476 temperature area that might experience below $28^{\circ} \mathrm{C} \mathrm{LST}$. Change of percentage of area is around $47722.18 \%$ which will fall within the range of LST greater than $32^{\circ} \mathrm{C}$ in 2039 (Table 11). The 478 prediction results demonstrate that most of the LST remains below $32^{\circ} \mathrm{C}$. Fig. $9 \mathrm{~b}$ shows the rising 479 trend of LST in the study area for the year 2039.

480 Table 11: Percentage Change of LSTs in the Study Area from 2019-2039

\begin{tabular}{cccccc}
\hline Range & $\begin{array}{c}\text { Area km } \\
(2019)\end{array}$ & $\begin{array}{c}\text { Area in } \\
\text { Percentage }\end{array}$ & $\begin{array}{c}\text { Area km } \\
(2039)\end{array}$ & $\begin{array}{c}\text { Area in } \\
\text { Percentage }\end{array}$ & $\begin{array}{c}\text { Change in Percentage } \\
(2039-2019)\end{array}$ \\
\hline$<20^{\circ} \mathrm{C}$ & - & - & - & - & - \\
$20-24^{\circ} \mathrm{C}$ & - & - & - & - & - \\
$24-28^{\circ} \mathrm{C}$ & 4.46 & 9.13 & 1.80 & 3.69 & -5.44
\end{tabular}




$\begin{array}{cccccc}28-32^{\circ} \mathrm{C} & 43.64 & 89.36 & 35.46 & 72.62 & -16.74 \\ >32^{\circ} \mathrm{C} & 0.74 & 1.51 & 11.57 & 23.69 & 22.18 \\ \text { Total } & 48.83 & 100 & 48.83 & 100 & \end{array}$

481 This effect of high LST is going to be a worrying problem for the study area. The temperature 482 effect depends on the city geometry and Dhaka City's unexpected growth triggers this devastating 483 impact of the increase of LST.

(a)

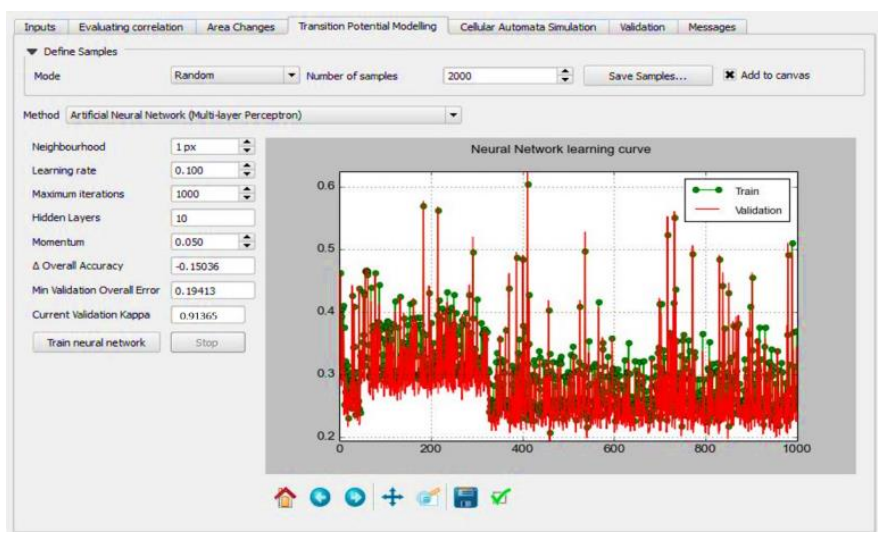

(b)

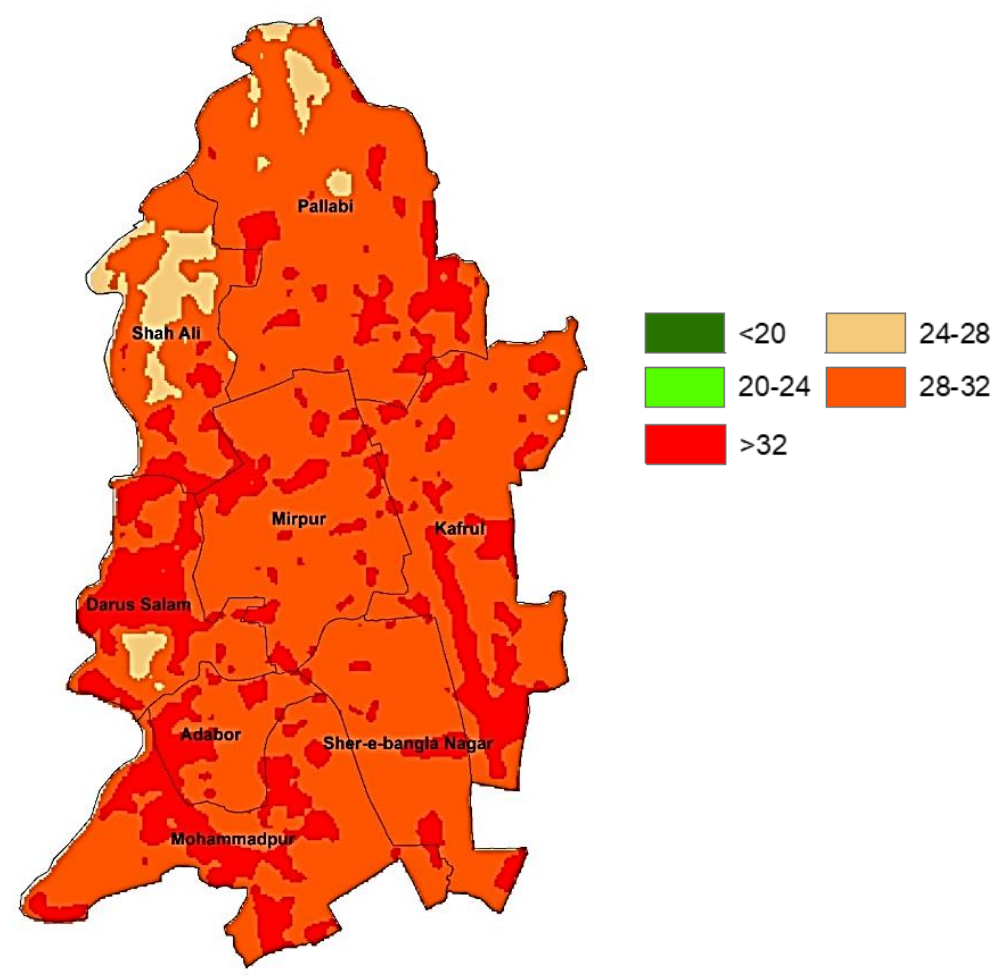

484 Fig. 9: (a) LST Prediction Model Validation Result for the Year 2039 and (b) Simulated LST Map for the year 2039

\section{4. Conclusions and Recommendations}

487 The study area faced tremendous increase of built-up area. Increasing impervious layers trend to 488 reflect and generate higher surface temperature. Considering the year 2014-2019, built-up area 489 gained $7.499 \%$ area where bare land, vegetation and water bodies were lost $6.679 \%, 0.383 \%$ and $490 \quad 0.440 \%$ area, respectively. The maximum losses (bare land and vegetation) and gains (built up 
491 area) were observed in the 2004-2014 period. However, the water body expansively was lost its 492 coverage in the 1994-1999 periods.

493 The average surface temperature increasing rate is high in 5 years interval period. In 1989, $49488.284 \%$ of area was covered under $20^{\circ} \mathrm{C}$ temperature. Later, maximum area of temperature was 495 increased to the range of $28-32^{\circ} \mathrm{C}$ at $52.136 \%$ from the year 2009 to 2014 . Here, $1.273 \%$ and $4960.238 \%$ area were increased to more than $32^{\circ} \mathrm{C}$ from the year 2009 to 2014 and from 2014 to 2019 , 497 respectively. The increase of built-up area, reduction of surface water bodies and vegetation land 498 were dominant from the year 2009 which contribute to the increase in the LST up to more than $49932^{\circ} \mathrm{C}$ from the year 2009. Validation of LST estimated data with BMD data was pretty much 500 impressive and the percentage of error is 3 to $4 \%$.

501 Prediction indicates that in the year 2039 approximately 92.42\% of Mirpur and surrounding areas 502 will be covered by built-up area and corresponding predicted LST range will be greater than $32^{\circ} \mathrm{C}$. 503 The prediction exhibited that approximately $23.69 \%$ of Mirpur area likely to have LST greater 504 than $32^{\circ} \mathrm{C}$ and $72.62 \%$ area is likely to remain $28-32^{\circ} \mathrm{C}$ LST range. There may not be any 505 temperature area that might experience below $28^{\circ} \mathrm{C}$ LST. Change of percentage of area is around $50622.18 \%$ which will fall within the range of LST greater than $32^{\circ} \mathrm{C}$ in 2039 . The prediction results 507 demonstrate that most of the LST remains below $32^{\circ} \mathrm{C}$.

508 Cross section profile of LULC vs LST shows higher temperature existed in built-up area in all 509 time periods. In the year $2019,0.61$ sq. $\mathrm{km}$ of urban area was fallen more than $32^{0} \mathrm{C}$ temperature 510 range followed by 40.94 sq. $\mathrm{km}$ in the range of $28-32^{\circ} \mathrm{C}$. LST has strong and positive correlation 511 with NDBI. LST has strong and negative correlation with NDVI. In all the correlation analysis, 512 the $\mathrm{R}^{2}$ found more than 0.9 that means the variables are strongly correlated with each other. The 513 study shows a clear past and present situation of the negative consequence of unplanned rapid 514 urbanization as well as predicts the future scenario of the study region.

515 The overall result shows a high LST change in the study area. Mirpur area is located in the DMP 516 area which is the most economically productive area of this country. Therefore, preparation steps 517 to reduce LST as well as UHI effects is important. The seasonal change of LST in the study area, 518 which in a tropical country is very uncertain, needs cloud-free satellite images. In summer region, 519 cloud contains the whole study region. If summer images could be collected, then actual LST 
520 effects can easily be realized. In addition, to understand the magnitude, it is necessary to evaluate

521 UHI locally and nationwide.

522 To the Author's knowledge, this is the first research to provide a method for estimating future LST

523 of metropolitan areas from observable connections between land cover and LST changes in the

524 study region. Since a result, future city planning should place a greater emphasis on urban

525 greening, as the research region increasingly shifts towards the highest temperature zone owing to

526 urbanization. If current trends continue, by 2039, nearly the whole study region will be a UHI. A

527 compact-town-style decentralization of metropolitan regions (satellite-towns) is therefore a viable

528 path ahead for preventing the future creation of large-scale UHI effects. The work derived future

529 LST using LULC indices (NDVI and NDBI) and a simple regression equation. It is feasible to

530 combine the various land cover indices as independent variables in a multiple regression equation

531 model in order to calculate the LST in a more robust manner, potentially using factor analysis.

532 Future research should integrate these elements and strive to improve upon the model given here.

\section{Acknowledgment}

534 All praises to Allah the benevolent, the Almighty, and the kind. We wish to express my profound 535 gratitude and sincere appreciation to Mohammad Shahriyar Parvez, Research Assistant, 536 Department of Civil Engineering, Military Institute of Science and Technology (MIST), for his 537 untiring help in preparing this research work.

\section{Contributions}

539 A N M Foyezur Rahman: methodology, software, data curation, writing-original draft 540 preparation.

541 M Tauhid Ur Rahman: conceptualization, methodology, writing — review \& editing.

\section{Ethics approval}

543 Not applicable

\section{Consent to participate}




\section{Consent for publication}

547 Agree to publish

548 Competing interests

549 The author declares that this research work is his original work and has written it in its entirety.

550 He has duly acknowledged all the sources of information that have been used in the paper.

\section{$551 \quad$ Funding}

552 This study was not funded.

\section{Data Availability}

554 The datasets used and analysed during the current study are available from the corresponding 555 author on reasonable request.

\section{References}

Ahmed, B. (2011a). Modelling spatio-temporal urban land cover growth dynamics using remote sensing and GIS techniques: A case study of Khulna City. Journal of Bangladesh institute of Planners, 4, 15-32.

Ahmed, B., Kamruzzaman, M., Zhu, X., Rahman, M. S., \& Choi, K. (2013). Simulating land cover changes and their impacts on land surface temperature in Dhaka, Bangladesh. Remote Sensing, 5(11), 5969-5998.

Ahmed, B. (2011b). Urban land cover change detection analysis and modeling spatio-temporal Growth dynamics using Remote Sensing and GIS Techniques: A case study of Dhaka, Bangladesh.

Al-sharif, A. A. A., \& Pradhan, B. (2014). Monitoring and predicting land use change in Tripoli Metropolitan City using an integrated Markov chain and cellular automata models in GIS. Arabian journal of geosciences, 7(10), 4291-4301. 
Amiri, R., Weng, Q., Alimohammadi, A., \& Alavipanah, S. K. (2009). Spatial-temporal dynamics of land surface temperature in relation to fractional vegetation cover and land use/cover in the Tabriz urban area, Iran. Remote sensing of environment, 113(12), 2606-2617.

Arsanjani, J. J., Helbich, M., Kainz, W., \& Boloorani, A. D. (2013). Integration of logistic regression, Markov chain and cellular automata models to simulate urban expansion. International Journal of Applied Earth Observation and Geoinformation, 21, 265-275.

Avdan, U., \& Jovanovska, G. (2016). Algorithm for automated mapping of land surface temperature using LANDSAT 8 satellite data. Journal of Sensors, 2016.

Bahi, H., Rhinane, H., Bensalmia, A., Fehrenbach, U., \& Scherer, D. (2016). Effects of urbanization and seasonal cycle on the surface urban heat island patterns in the coastal growing cities: A case study of Casablanca, Morocco. Remote Sensing, 8(10), 829.

Balogun, I., \& Ishola, K. (2017). Projection of future changes in landuse/landcover using cellular automata/markov model over Akure city, Nigeria. Journal of Remote Sensing Technology, $5(1), 22-31$.

Celik, B., Kaya, S., Alganci, U., \& Seker, D. Z. (2019). Assessment of the Relationship Between Land Use/Cover Changes and Land Surface Temperatures: A case study of Thermal Remote Sensing. FEB-FRESENIUS ENVIRONMENTAL BULLETIN, 3, 541.

Chander, G., Markham, B. L., \& Helder, D. L. (2009). Summary of current radiometric calibration coefficients for Landsat MSS, TM, ETM+, and EO-1 ALI sensors. Remote sensing of environment, 113(5), 893-903.

Chaudhuri, G., \& Mishra, N. B. (2016). Spatio-temporal dynamics of land cover and land surface temperature in Ganges-Brahmaputra delta: A comparative analysis between India and Bangladesh. Applied geography, 68, 68-83.

Chen, X.-L., Zhao, H.-M., Li, P.-X., \& Yin, Z.-Y. (2006). Remote sensing image-based analysis of the relationship between urban heat island and land use/cover changes. Remote sensing of environment, 104(2), 133-146.

Civco, D. L. (1993). Artificial neural networks for land-cover classification and mapping. International journal of geographical information science, 7(2), 173-186.

Congalton, R. G., \& Green, K. (2008). Assessing the accuracy of remotely sensed data: principles and practices: CRC press. 
Corner, R. J., Dewan, A. M., \& Chakma, S. (2014). Monitoring and prediction of land-use and land-cover (LULC) change. In Dhaka megacity (pp. 75-97): Springer.

d'Entremont, R. P., \& Thomason, L. W. (1987). Interpreting meteorological satellite images using a color-composite technique. Bulletin of the American Meteorological Society, 68(7), 762768.

Foody, G. M. (2002). Status of land cover classification accuracy assessment. Remote sensing of environment, 80(1), 185-201.

Dewan, A. M., Kabir, M. H., Nahar, K., \& Rahman, M. Z. (2012). Urbanisation and environmental degradation in Dhaka Metropolitan Area of Bangladesh. International Journal of Environment and Sustainable Development, 11(2), 118-147.

Dewan, A. M., \& Yamaguchi, Y. (2009). Land use and land cover change in Greater Dhaka, Bangladesh: Using remote sensing to promote sustainable urbanization. Applied geography, 29(3), 390-401.

Fu, P., \& Weng, Q. (2018). Responses of urban heat island in Atlanta to different land-use scenarios. Theoretical and applied climatology, 133(1-2), 123-135.

Good, T., \& Giordano, P. A. (2019). Methods for constructing a color composite image. In: Google Patents.

Gopal, S., \& Woodcock, C. (1996). Remote sensing of forest change using artificial neural networks. IEEE Transactions on Geoscience and Remote Sensing, 34(2), 398-404.

Grimmond, S. U. E. (2007). Urbanization and global environmental change: local effects of urban warming. Geographical Journal, 173(1), 83-88.

Gutman, G., Huang, C., Chander, G., Noojipady, P., \& Masek, J. G. (2013). Assessment of the NASA-USGS global land survey (GLS) datasets. Remote sensing of environment, 134, 249-265.

Handayanto, R. T., Kim, S. M., \& Tripathi, N. K. (2017, 2017). Land use growth simulation and optimization in the urban area.

Hart, M. A., \& Sailor, D. J. (2009). Quantifying the influence of land-use and surface characteristics on spatial variability in the urban heat island. Theoretical and applied climatology, 95(3-4), 397-406.

IPCC. (2014). Mitigation of climate change. Contribution of Working Group III to the Fifth Assessment Report of the Intergovernmental Panel on Climate Change, 1454. 
Islam, M. S., \& Ahmed, R. (2011). Land use change prediction in Dhaka city using GIS aided Markov chain modeling. Journal of Life and Earth Science, 6, 81-89.

Kafy, A., Islam, M., Ferdous, L., Khan, A. R., \& Hossain, M. M. (2019). Identifying Most Influential Land Use Parameters Contributing Reduction of Surface Water Bodies in Rajshahi City, Bangladesh: A Remote Sensing Approach. Remote Sensing of Land, 2(2), 87-95. doi:http://dx.doi.org/10.21523/gcj1.18020202

Lambin, E. F. (1999). Land-use and land-cover Change (LUCC)-implementation strategy. A core project of the International Geosphere-Biosphere Programme and the International Human Dimensions Programme on Global Environmental Change.

Li, J., \& Zhao, H. (2003). Detecting urban land-use and land-cover changes in Mississauga using Landsat TM images. Journal of Environmental Informatics, 2(1), 38-47.

Li, Z.-L., Tang, B.-H., Wu, H., Ren, H., Yan, G., Wan, Z., . . Sobrino, J. A. (2013). Satellitederived land surface temperature: Current status and perspectives. Remote sensing of environment, 131, 14-37.

Lilly Rose, A., Devadas, M.D., . , . (2009). Analysis of Land Surface Temperature and Land Use/Land Cover Types Using Remote Sensing Imagery - A Case In Chennai City,

India. Paper presented at the The seventh International Conference on Urban Climate., held on 29 June - 3 July 2009, Yokohama, Japan.

Liu, L., \& Zhang, Y. (2011). Urban heat island analysis using the Landsat TM data and ASTER data: A case study in Hong Kong. Remote Sensing, 3(7), 1535-1552.

Maduako, I. D., Yun, Z., \& Patrick, B. (2016). Simulation and prediction of land surface temperature (LST) dynamics within Ikom City in Nigeria using artificial neural network (ANN). Journal of Remote Sensing \& GIS, 5(1), 1-7.

Maimaitiyiming, M., Ghulam, A., Tiyip, T., Pla, F., Latorre-Carmona, P., Halik, Ü., . . Caetano, M. (2014). Effects of green space spatial pattern on land surface temperature: Implications for sustainable urban planning and climate change adaptation. ISPRS journal of photogrammetry and remote sensing, 89, 59-66.

McKinney, M. L. (2002). Urbanization, biodiversity, and conservation. Bioscience 52: 883890 McKinney ML (2006) Urbanization as a major cause of biotic homogenization. Biol Conserv, 127, 247260. 
Meyer, W. B., \& Turner, B. L. (1992). Human population growth and global land-use/cover change. Annual review of ecology and systematics, 23(1), 39-61.

Mishra, V. N., \& Rai, P. K. (2016). A remote sensing aided multi-layer perceptron-Markov chain analysis for land use and land cover change prediction in Patna district (Bihar), India. Arabian journal of geosciences, 9(4), 249.

Mondal, M. S., Sharma, N., Garg, P., \& Kappas, M. (2016). Statistical independence test and validation of CA Markov land use land cover (LULC) prediction results. The Egyptian Journal of Remote Sensing and Space Science, 19(2), 259-272.

Rahman, M. (2016). Detection of land use/land cover changes and urban sprawl in Al-Khobar, Saudi Arabia: An analysis of multi-temporal remote sensing data. ISPRS International Journal of Geo-Information, 5(2), 15.

Rahman, M. S., Mohiuddin, H., Kafy, A.-A., Sheel, P. K., \& Di, L. (2018). Classification of cities in Bangladesh based on remote sensing derived spatial characteristics. Journal of Urban Management.

Rahman, M. T., Aldosary, A. S., \& Mortoja, M. (2017). Modeling future land cover changes and their effects on the land surface temperatures in the Saudi Arabian eastern coastal city of Dammam. Land, 6(2), 36. 
Rahman, M. T., \& Rashed, T. (2015). Urban tree damage estimation using airborne laser scanner data and geographic information systems: An example from 2007 Oklahoma ice storm. Urban Forestry \& Urban Greening, 14(3), 562-572.

Santé, I., García, A. M., Miranda, D., \& Crecente, R. (2010). Cellular automata models for the simulation of real-world urban processes: A review and analysis. Landscape and urban planning, 96(2), 108-122.

Scarano, M., \& Sobrino, J. A. (2015). On the relationship between the sky view factor and the land surface temperature derived by Landsat-8 images in Bari, Italy. International Journal of Remote Sensing, 36(19-20), 4820-4835.

Shatnawi, N., \& Abu Qdais, H. (2019). Mapping urban land surface temperature using remote sensing techniques and artificial neural network modelling. International Journal of Remote Sensing, 1-16.

Sholihah, R. I., \& Shibata, S. (2019). Retrieving Spatial Variation of Land Surface Temperature Based on Landsat OLI/TIRS: A Case of Southern part of Jember, Java, Indonesia. Paper presented at the IOP Conference Series: Earth and Environmental Science.

Story, M., \& Congalton, R. G. (1986). Accuracy assessment: a user's perspective. Photogrammetric Engineering and remote sensing, 52(3), 397-399.

Streutker, D. R. (2003). Satellite-measured growth of the urban heat island of Houston, Texas. Remote sensing of environment, 85(3), 282-289.

Thapa, R., \& Murayama, Y. (2009). Examining spatiotemporal urbanization patterns in Kathmandu Valley, Nepal: Remote sensing and spatial metrics approaches. Remote Sensing, 1(3), 534-556.

Tran, D. X., Pla, F., Latorre-Carmona, P., Myint, S. W., Caetano, M., \& Kieu, H. V. (2017). Characterizing the relationship between land use land cover change and land surface temperature. ISPRS journal of photogrammetry and remote sensing, 124, 119-132.

Ullah, S., Tahir, A. A., Akbar, T. A., Hassan, Q. K., Dewan, A., Khan, A. J., \& Khan, M. (2019). Remote sensing-based quantification of the relationships between land use land cover changes and surface temperature over the lower Himalayan region. Sustainability, 11(19), 5492.

van Scheltinga, C. T., Quadir, D. A., \& Ludwig, F. (2015). Baseline Study Climate ChangeBangladesh Delta Plan. Retrieved from 
721 Weng, Q., Lu, D., \& Schubring, J. (2004). Estimation of land surface temperature-vegetation 722 abundance relationship for urban heat island studies. Remote sensing of environment, 723 89(4), 467-483.

724 Xiong, Y., Huang, S., Chen, F., Ye, H., Wang, C., \& Zhu, C. (2012). The impacts of rapid 725 urbanization on the thermal environment: A remote sensing study of Guangzhou, South China. Remote Sensing, 4(7), 2033-2056.

727 Yu, X., Guo, X., \& Wu, Z. (2014). Land surface temperature retrieval from Landsat 8 TIRS728 Comparison between radiative transfer equation-based method, split window algorithm and single channel method. Remote Sensing, 6(10), 9829-9852.

730 Zheng, H. W., Shen, G. Q., Wang, H., \& Hong, J. (2015). Simulating land use change in urban renewal areas: A case study in Hong Kong. Habitat International, 46, 23-34.

732 Zhi-hao, Q., Wen-juan, L., Ming-hua, Z., Karnieli, A., \& Berliner, P. (2011). Estimating of the 733 essential atmospheric parameters of mono-window algorithm for land surface temperature retrieval from Landsat TM 6. Remote Sensing for Land \& Resources, 15(2), 37-43.

735 Zhou, W., Huang, G., \& Cadenasso, M. L. (2011). Does spatial configuration matter? Understanding the effects of land cover pattern on land surface temperature in urban landscapes. Landscape and urban planning, 102(1), 54-63. (2014). Heat wave hazard modelling: Qatar case study. QScience connect, 9. 